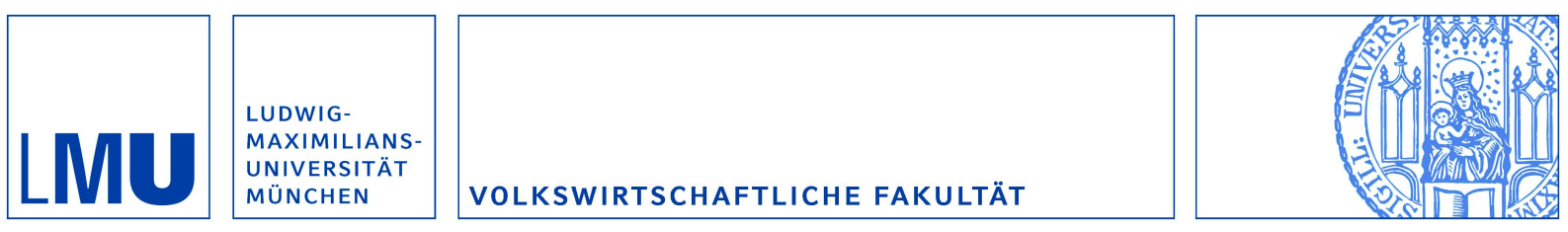

Sauer, Stephan:

Liquidity Risk and Monetary Policy

Munich Discussion Paper No. 2007-27

Department of Economics

University of Munich

Volkswirtschaftliche Fakultät

Ludwig-Maximilians-Universität München

Online at https://doi.org/10.5282/ubm/epub.2012 


\title{
Liquidity Risk and Monetary Policy
}

\author{
Stephan Sauer* \\ Seminar for Macroeconomics \\ University of Munich \\ Germany
}

August 2007

\begin{abstract}
This paper provides a framework to analyse emergency liquidity assistance of central banks on financial markets in response to aggregate and idiosyncratic liquidity shocks. The model combines the microeconomic view of liquidity as the ability to sell assets quickly and at low costs and the macroeconomic view of liquidity as a medium of exchange that influences the aggregate price level of goods. The central bank faces a trade-off between limiting the negative output effects of dramatic asset price declines and more inflation. Furthermore, the anticipation of central bank intervention causes a moral hazard effect with investors. This gives rise to the possibility of an optimal monetary policy under commitment.
\end{abstract}

Keywords: Liquidity shocks, Financial crises, Liquidity provision principle, Greenspan put, Optimal monetary policy intervention.

JEL classification: E58, E44, G18.

\footnotetext{
*I would like to thank Gerhard Illing for fruitful discussions and Marco Sahm for helpful comments. Address for correspondence: Seminar for Macroeconomics, University of Munich, Ludwigstr. 28 RG, 80539 Munich, Germany. E-mail: stephan.sauer@lrz.uni-muenchen.de.
} 


\section{Introduction}

Liquidity is an important concept in finance and macroeconomics. The microeconomic literature in finance views liquidity roughly as the ability to sell assets quickly and costlessly. In macroeconomics, liquidity refers to a generally accepted medium of exchange or, in brief, money. Money is the most liquid asset due to the fact that it does not need to be converted into anything else in order to make purchases of real goods or other assets. This feature makes money valuable in both perspectives.

This paper uses this common perspective of money and links liquidity risk on an asset market with aggregate demand and aggregate supply on a goods market. Spillover effects from the asset market to the goods market can justify a central bank intervention on the asset market even if the central bank does not take the welfare of investors on the asset market into account. Hence, the model provides a framework to analyse the perceived insurance against severe financial turmoil by the Federal Reserve under Alan Greenspan, which has been termed the 'Greenspan put' in the popular press and 'liquidity provision principle' by Taylor (2005).

Liquidity provision has been studied in the literature with a focus on the role of financial intermediaries (see, e.g., Diamond and Dybvig, 1983; Allen and Gale, 1998; Diamond and Rajan, 2001, 2005; Goodhart and Illing, 2002). Considerably less research looked at liquidity provision by financial markets (see, e.g., Allen and Gale, 1994; Holmström and Tirole, 1998). Furthermore, all of these papers use models with real assets and claims. If the aim is to analyse optimal monetary interventions on financial markets, however, it seems to be natural that one has to use a model in nominal units, since the central bank can provide nominal fiat money but not real goods. Only recently, Gale (2005) and Diamond and Rajan (2006) have made first steps in that direction and developed models with nominal assets. ${ }^{1}$ Contributing to this literature, I develop an analytical framework based on the cash-in-the-market pricing model of Allen and Gale $(1994,2005)$ that directly links monetary policy and liquidity on financial markets.

Before I turn to the details of the model, the following two sections provide empirical and historical evidence of the role of liquidity on asset prices and in financial crises.

\footnotetext{
${ }^{1}$ Allen and Gale (1998) contains discussions about both monetary policy to limit some inefficiencies of bank runs and the effects of an asset market. Gale $(2005$, p. 2) himself, however, argues that this and more recent papers by Allen and Gale that use the same methodology are 'essentially real (non-monetary) models' and 'focus on banks and banking, to the exclusion of other parts of the financial system.'
} 


\subsection{Empirical evidence for the role of liquidity on asset prices}

One of the first studies that empirically links asset pricing and liquidity is Amihud and Mendelson (1986), who show that shares' excess returns increase in the size of the average bid-ask spread, a well-known measure of an asset's level of liquidity. Recent research has provided further important empirical evidence on the relevance of time-varying market-wide liquidity on asset pricing and of the effects of monetary expansions on liquidity during crisis periods.

Pastor and Stambaugh (2003) measure market liquidity as the equally weighted average of individual shares' expected return reversal. The authors start from the idea that a sell (buy) order should be accompanied by a negative (positive) price impact that one expects to be partially reversed in the future if the share is not perfectly liquid. Sharp declines in this measure coincide with market declines and 'flight to quality' or 'flight to liquidity' episodes in which investors want to shift from relatively illiquid medium to long-term assets such as shares into safe and liquid government bonds or cash. Examples of such incidents are discussed in the following section 1.2. Market-wide liquidity as measured by Pastor and Stambaugh (2003) appears to be a state variable that is important for share prices. Shares whose returns are more sensitive to aggregate liquidity have substantially higher expected returns, even as the authors control for exposures to the market, size and value factors of Fama and French (1993) and a momentum factor.

Acharya and Pedersen (2005) derive and estimate a liquidity-adjusted capital asset pricing model. In addition to the standard market beta, their model has three betas representing different forms of liquidity risk. One beta resembles the analysis in Pastor and Stambaugh (2003): Investors are willing to accept a lower expected return on an asset with a high return in times of market illiquidity. Futhermore, Acharya and Pedersen (2005) show that investors require a higher expected return for a security that becomes illiquid when the market in general becomes illiquid. Finally, investors require a lower expected return for an asset that is liquid if the market return is low. In the authors' estimations, the last effect appears to have the strongest impact on expected returns.

Most importantly for this paper, Chordia, Sarkar and Subrahmanyam (2005) establish an empirical link between the macro- and the micro-perspective of liquidity. The authors find that 'money flows (...) account for part of the commonality in stock and bond market liquidity.' Furthermore, they use vector autoregressions to provide evidence that a loose monetary policy, measured as a decrease in net borrowed reserves or a negative interest rate surprise, ${ }^{2}$ is as-

\footnotetext{
${ }^{2}$ Net borrowed reserves represent the difference between the amount of reserves banks need to have to satisfy their reserve requirements and the amount which the Fed is willing to supply. A negative interest rate surprise is defined as a drop of the federal funds target rate below market
} 
sociated with lower bid-ask spreads, i.e. increased liquidity, in times of crises.

\subsection{Historical liquidity crises and central banks' reactions}

Besides these empirical studies, there is also a lot of anecdotal evidence how central banks reacted to liquidity crises, since the last decades have shown a number of such crises on financial markets. For example, Davis (1994) describes five severe liquidity crises in international markets: The Penn Central Bankruptcy in 1970, the crisis in the floating-rate notes market in the UK in 1986, the failure of the US-High Yield bond market in 1989, the Swedish Commercial Paper crisis in 1990 and the collapse of the ECU bond market in 1992. Greenspan (2004) highlights three crises during his chairmanship at the Federal Reserve (Fed), in which market participants wanted to convert illiquid medium to long-term assets into cash because they favoured safety and liquidity over uncertainty: The stock market crash in 1987, the LTCM-crisis 1998 and the terrorist attacks of September 11, 2001. This section provides a brief review of these three events and the central banks', in particular the Fed's, reactions to them. Sauer (2007) contains a more detailed discussion of the events.

On 19 October 1987 ('Black Monday'), the Dow Jonex Index dropped by 22.6\%. Many commentators blamed institutional investors that followed a portfolio insurance investment strategy for the dramatic crash in prices. ${ }^{3}$ Similar to stoploss-orders, portfolio insurance implies automatic sell orders when the value of a portfolio or single shares falls below a certain threshold. If the absorption capacity of the market is limited, portfolio insurance can cause a vicious circle of price falls and further sell orders (see also section 4.3).

Grossman and Miller (1988) describe the events on 19 and 20 October against the background of their model in which market liquidity is determined by the demand and supply of immediacy, i.e. the willingness to trade immediately rather than to wait some time for a possibly better price. They argue that order imbalances were so great ${ }^{4}$ that market makers became incapable of supplying further immediacy. Market illiquidity materialised as delays in the execution and confirmation of trades and as the virtual impossibility of executing market sell orders at the quoted prices at the time of order entry.

As chairman of the Fed, Alan Greenspan managed to improve the confidence of investors and the liquidity of the market by issuing the following statement

expectations (Chordia et al., 2005, pp. 112-113).

${ }^{3}$ For example, Gammill and Marsh (1988) report official statistics that show that institutional investors who followed a portfolio insurance investment strategy were the heaviest net sellers on the New York Stock Exchange and in the S\&P 500 index futures market.

${ }^{4}$ After a more than $10 \%$ decline of the Dow Jones between Wednesday, 14 October, and Friday, 16 October, Gammill and Marsh (1988) note an 'overhang of incomplete portfolio selling' by portfolio insurers which caused additional selling pressure on the morning of Black Monday. 
at 9am on 20 October 1987:

The Federal Reserve, consistent with its responsibilities as the Nation's central bank, affirmed today its readiness to serve as a source of liquidity to support the economic and financial system (Greenspan, 1987).

The Dow Jones regained $5.9 \%$ and $10.1 \%$ on this and the following day, respectively. Garcia (1989) discusses the different tools the Fed used to limit the extent of the stock market crash. These included, besides communication via the quoted statement, mainly open market operations and the use of the discount window to provide liquidity in the form of additional money to the market. The handling of the crisis by Alan Greenspan, who was appointed as Fed Chairman only two months earlier, laid the foundations for the belief in an insurance against stock market losses, the alleged 'Greenspan put' (see also section 5.1).

In September 1998, the near-collapse of the hedge fund Long-term Capital Management (LTCM) caused severe turmoil on financial markets. ${ }^{5}$ After years of extraodinary performance, LTCM experienced below-average returns in 1997 and even losses in the first half of 1998. In response, LTCM increased its leverage, i.e. its debt/equity ratio, and focused even more on investments in relatively illiquid assets. The Russian default in August 1998 caused a flight to quality into liquid government bonds, while the prices of more illiquid assets fell dramatically. Margin calls forced LTCM to sell its assets into the falling market, which exacerbated the crisis. Other market participants could not (and some did not want to, see Brunnermeier and Pedersen, 2005) step in and buy assets, not least because they had copied LTCM's trading strategies and were constrained in their available funds. LTCM's supposedly sophisticated risk management system had not taken this endogeneity of risk sufficiently into account and its imminent collapse threatened the functioning of the Treasury bond market because of LTCM's large short-positions on this market.

On 23 September, the New York Fed organised a private bailout of LTCM by 14 banks that had lent to the fund. In the following weeks, the Fed lowered its policy rate three times by 25 basis points in order to provide sufficient liquidity for financial markets. Both Greenspan (2004) and Meyer (2004), who was on the Fed's Board of Governors at that time, admit that the purpose of these rate cuts was to calm financial markets rather than to stimulate the still expanding real economy. Indeed, the second cut boosted financial markets ${ }^{6}$ and, for example,

\footnotetext{
${ }^{5}$ For a more detailed analysis of the LTCM-crisis, see e.g. IMF (1998), Jorion (2000) or Sauer (2002).

${ }^{6}$ The cut was implemented between two scheduled meetings of the Federal Open Market Committee on 15 October 1998, a very rare step by the Fed under Alan Greenspan.
} 
considerably lowered spreads on repos, swaps, corporate bonds and off-therun treasuries, which all had increased dramatically after the Russian default (IMF, 1998, p. 39). Nevertheless, the Fed still feared the downside risks and lowered its policy rate a third time on 17 November despite lingering positive GDP data. Given the subsequent rise in inflation and equity prices until 2000, Meyer (2004, p. 121) later regretted this last cut.

The terrorist attacks in the morning of 11 September 2001 represented a very different form of a liquidity shock to financial markets. Liquidity evaporated from the financial system not because of margin calls, portfolio insurance strategies or a preference shock, but rather because large parts of the communication system and a lot of back offices in lower Manhattan were physically destroyed. One immediate response of the authorities was to leave the New York Stock Exchange, the American Stock Exchange and NASDAQ closed until 17 September. Hence, liquidity problems concentrated in the payment and settlement system and did not affect the stock market immediately. In that sense, the effects were limited and the Fed could quickly withdraw the additional 108 billion US-\$ in discount window credits, overnight repos and check floats it had supplied to banks until 13 September already by 20 September (Lacker, 2004, table 1).

In Europe, the European Central Bank (ECB) immediately issued the following press statement on 11 September:

After the unprecedented and tragic events in the United States today, the Eurosystem stands ready to support the normal functioning of the markets. In particular, the Eurosystem will provide liquidity to the markets, if need be. (ECB, 2001a)

Furthermore, the ECB conducted two one-day fine-tuning operations on 12 and 13 September with a volume of 69.3 and 40.5 billion Euro, respectively, in which all bids were satisfied. It also entered into a swap agreement with the Fed over 50 billion US-\$ to provide dollar liquidity to European banks on 12 September (ECB, 2001b). However, the ECB left its key interest rates unchanged on its regular meeting on 13 September.

Just before U.S. stock markets reopened on the morning of Monday 17 September, the Fed cut its target rate by 50 basis points. The ECB followed suit and also lowered its key interest rates by the same amount. The Fed continued to cut rates on 2 October, 6 November and 11 December, while the ECB reduced its rates only on 9 November. Although Lacker (2004, p. 961) argues that 'the [Fed] interest rate cuts following September 11 are probably best viewed as addressing the medium- and longer-term macroeconomic consequences' rather than a necessary response to disruptions in the payment system, the 
contemporaneous action of central banks worldwide on 17 September $^{7}$ hints that this move was also aimed at rebuilding confidence and signalling that central banks would continue to provide liquidity if necessary. Indeed, on 17 September the Dow Jones opened only 3.2\% below the closing value on 10 September. Until 21 September, the Dow lost 14.3\% compared to 10 September, but regained quickly in the following weeks and reached the pre-terrorist level already in October.

A common feature of these crises is that the Fed lowered its interest rate to provide emergency liquidity to the market, although the mandate of the Fed in the Humphrey-Hawkins Act of 1978 focuses on price stability and full employment. Taylor (1993) suggested a simple interest rate rule to capture these two goals:

$$
i_{t}=r_{t}^{*}+\pi_{t}+0.5\left(\pi_{t}-\pi_{t}^{*}\right)+0.5 y_{t} .
$$

The nominal interest rate $i_{t}$ should rise with the natural real rate $r_{t}^{*}$, inflation $\pi_{t}$ relative to its target rate $\pi_{t}^{*}$ and the output gap $y_{t}$. The comparison of the actual Fed funds target rate with the recommendation from this Taylor rule provides a simple test for the liquidity provision principle, i.e. a temporary departure of interest rates from the Taylor rule during financial crises (Taylor, 2005) in order to avoid negative spillover effects from the asset to the goods market. Figure 1 shows that the Fed decreased its policy rate in the months following all three crises as noted above. The Taylor rule, however, recommended a rise of the interest rate after the crises of 1987 and 1998. Therefore, monetary policy appears expansionary for about six months until April 1988 and even more so after the LTCM-crisis 1998. In contrast, the Taylor rate matches the actual Fed funds rate after the terrorist attacks in 2001 quite closely. From the beginning of 2002, actual monetary policy looks even restrictive compared to the Taylor rule.

Figure 2 reveals considerable differences in the development of inflation in the aftermath of the crises. For comparison, inflation is measured as the annual growth rate of both the consumer price index (CPI) and the personal consumption expenditure index (PCE), but the differences appear to be negligible. The average inflation rate one and a half to two years after the crises compared to average inflation in the six months up to the crises increased by 0.8 percentage points after 1987 and 1.7 points after $1998 .^{8}$ In contrast, inflation decreased by 0.4 (PCE) or 0.9 (CPI) points after 2001. Therefore, expansionary monetary policy via the liquidity provision principle appears to have contributed to price

\footnotetext{
${ }^{7}$ Besides the Fed and the ECB, also the Bank of England, the Swedish Riksbank, the Bank of Canada and other central banks worldwide lowered their policy rates on the same day.

${ }^{8}$ Besides the rise in consumer prices, expansionary monetary policy may also have contributed to the boom and bust period of equity prices in the five years following the LTCM-crisis.
} 

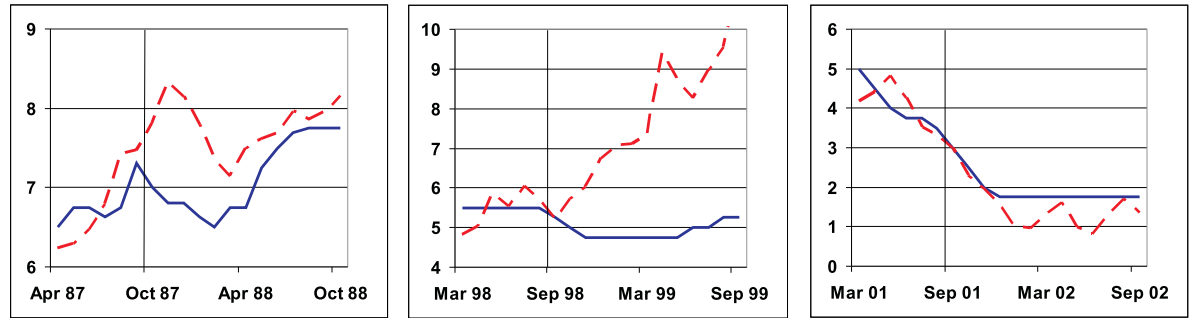

Figure 1: Federal funds target rate (solid line) and Taylor rule rate (dashed line) in the U.S. during the crises in 1987, 1998 and 2001.

Notes: The Taylor rule rate is based on equation (1) with $\pi_{t}$ measured as the annual growth rate of the consumer price index and $y_{t}$ measured as the quarterly OECD-output gap transformed into monthly data with a cubic spline. The Taylor rate is adjusted for time-varying $r_{t}^{*}$ and $\pi_{t}^{*}$ by matching the average Taylor rate in the six months prior to the respective crisis with the average Federal funds target rate over this period. Data source: Thomson Financial Datastream.
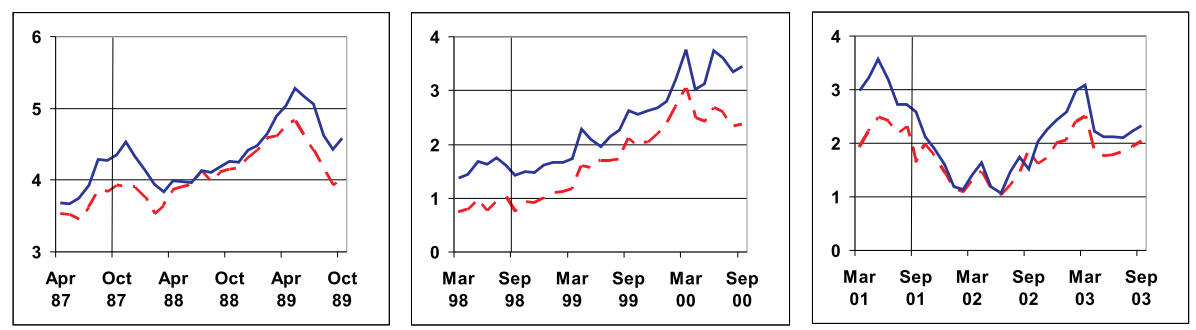

Figure 2: CPI (solid line) and PCE (dashed line) inflation rates in the U.S. after the crises in 1987, 1998 and 2001.

Notes: Inflation is measured as the annual growth rate of the consumer price index (CPI) and the personal consumption expenditure index (PCE). Data source: Thomson Financial Datastream.

increases after 1987 and 1998, while a normal or even restrictive stance of monetary policy added to a decline of inflation after 2001.

All three historical episodes of liquidity crises demonstrate that central banks, and in particular the Fed under Alan Greenspan, stood ready to provide liquidity in times of financial crises. Greenspan $(2004$, p. 38) states that the 'immediate response on the part of the central bank to such financial implosions must be to inject large quantities of liquidity,' in line with the traditional Bagehot (1873) principle for a lender of last resort activity to 'lend freely at a high rate against good collateral.' But the events also indicate that not all financial crises are alike and central banks face a difficult task to decide on the optimal policy, which depends on the associated cost and benefits. The rest of this paper develops a stylised model of an asset market and a goods market which provides a framework to analyse the relevant trade-offs for the central bank. 


\subsection{The model in a nutshell}

The model consists of two separate markets, an asset market and a goods market. The main focus is on developments on the asset market, but these developments have important implications for the goods market. Although the monetary authority only cares about deviations of goods prices and quantities from the optimal values, the spillover effects from the asset market may require a central bank intervention on this market.

In the model, investors can invest on an asset market in liquid money and potentially illiquid, but productive assets, called shares, in order to optimally satisfy their uncertain consumption needs on the goods market over two periods. Two channels link the goods market to the asset market: First, the amount of money held by investors determines together with the size of a liquidity shock the aggregate demand of investors on the goods market which is subject to a cash-in-advance constraint. Second, a dramatic decrease of the asset price negatively influences the goods supply in the final period because it forces investors to costly liquidate their asset. Hence, the central bank faces a trade-off between inflating a demand shock today, which causes higher losses today, and limiting a negative supply shock tomorrow, which will cause higher losses tomorrow. Expectations of central bank intervention give rise to a moral hazard effect with additional investment in less liquid, but productive shares. If the central bank has the possibility to commit to some future policy, it should optimally weight these productivity gains against the expected intervention costs. Section 2 analyses the basic model under certainty and aggregate risk. Section 3 provides further insights into the trade-off the central bank faces and derives the optimal central bank intervention before section 4 discusses the impact of idiosyncratic risk. After the discussion of the related literature in section 5, section 6 concludes.

\section{Model}

\subsection{Framework}

A continuum of ex ante identical investors $i$ is uniformally distributed on an intervall $I=[0 ; 1]$. They can invest on an asset market and buy goods for consumption on a separate goods market. An investor $i$ derives utility from consumption $c_{t}$ in periods $t=1,2$ according to the utility function

$$
U_{i}\left(c_{1}, c_{2}\right)=\gamma \zeta_{i} \ln c_{1}+\beta \ln c_{2} .
$$


Table 1: Payoffs of money and shares in $t=0,1,2$.

\begin{tabular}{|c|c|c|c|}
\hline & 0 & 1 & 2 \\
\hline \multirow{2}{*}{$m=w-s$} & \multirow{2}{*}{-1} & 1 & 0 \\
\hline & & 0 & 1 \\
\hline \multirow{3}{*}{$s$} & \multirow{3}{*}{-1} & $q$ & 0 \\
\hline & & 0 & $R$ \\
\hline & & $\rho$ & 0 \\
\hline
\end{tabular}

$\gamma \zeta_{i}$ represents a liquidity shock that consists of an aggregate liquidity shock $\gamma$ and an individual liquidity shock $\zeta_{i}$. The distribution functions of both shocks are assumed to be uncorrelated, symmetric, having a positive support and an expected value of 1 in $t=0$, i.e. $E_{0}\left[\gamma \zeta_{i}\right]=\int_{-\infty}^{\infty} \gamma f(\gamma) d \gamma \cdot \int_{-\infty}^{\infty} \zeta_{i} f\left(\zeta_{i}\right) d \zeta_{i}=1$. Every investor is endowed with nominal wealth $w$ that can be invested in $t=0$ in nominal money $m$ and a real asset $s$, called shares, on a primary market with price $q_{0}=1$ fixed and $s$ endogenous. The asset pays a fixed nominal return $R$ in $t=2$ and can be traded at the nominal price $q$ on a secondary asset market in $t=1$ after the realisation of the liquidity shock $\gamma \zeta_{i}$, but before goods are traded on the goods market. Besides, investors have access to a costly real liquidation technique, which transforms $z$ units of the asset $s$ into $\rho z$ units of additional consumption goods in period 1 with $\rho<1$. The individual cost of liquidation is the missed nominal return $R z$ in $t=2$ and the social cost is a reduction of aggregate supply in $t=2$ by $\Delta(z) .{ }^{9}$ The asset $s$ can also be interpreted as a nominal bond with a fixed interest rate $R$ and a real put option with a strike price of $\rho$. Table 1 summarises the payoffs of $m$ and $s$ in $t=0,1,2$.

At the beginning of $t=1$ and 2, homogenous, infinitely divisible and nonstorable consumption goods are produced with capital and labour input from workers who can participate only on the goods market and receive a nominal wage $\psi_{t}$ that is determined at $t-1 .{ }^{10}$ These goods must be bought by investors and workers with money, i.e. they are subject to a cash-in-advance constraint. The price of consumption goods $p_{t}$ is determined by demand for goods from workers and investors and the aggregate supply of goods. Markets are com-

\footnotetext{
${ }^{9}$ For example, Shleifer and Vishny (1992) and Allen and Gale (1998) contain a discussion of the costs of premature liquidation of assets. The costly liquidation technology shall represent investors possibility to a) partly liquidate their capital, b) sell their capital to less productive owners or c) cut down replacement investments because firms' refinancing possibilities depend on their share price as in the financial accelerator model by Bernanke, Gertler and Gilchrist (1999). In this model, the assumption $\rho<1$ guarantees that money is not fully dominated by the asset given the price determination on the goods market as explained in section 2.2.2 and the absence of central bank interventions. For the corresponding condition with central bank intervention, see Corollary 2 on page 29.

${ }^{10}$ Section 5.2 discusses the literature on market segmentation.
} 
Asset market

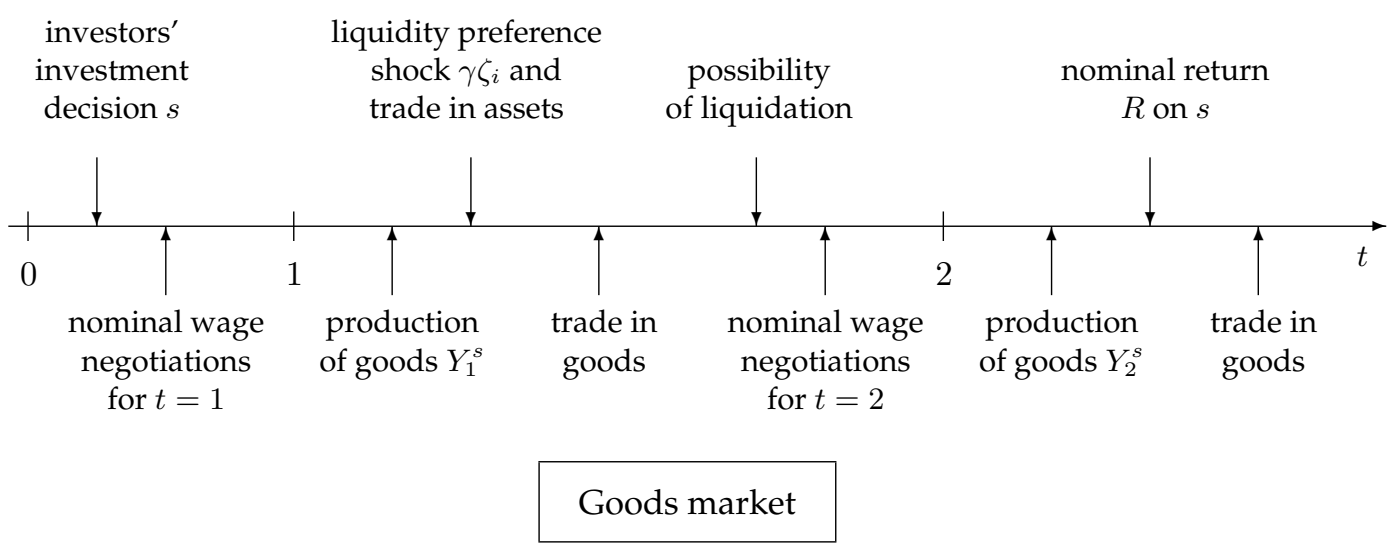

Figure 3: Time structure of the model.

petitive but incomplete. Figure 3 summarises the timing of the model.

\subsection{Under Certainty}

\subsubsection{Investors' problem and asset market}

Before I analyse the effects of liquidity shocks $\gamma \zeta_{i}$, I solve the model under certainty, i.e. $\gamma=\zeta_{i}=1$. The individual investor maximises her utility function (2) subject to her budget constraint and her cash-in-advance constraint (CIA) in $t=1 .{ }^{11}$ She controls her initial investment in the asset $s$, her consumption $c_{t}$ in $t=1$ and 2 bought on the goods market with cash, her demand for additional assets in $t=1, \hat{s}$, and the extent of costly liquidation $z$, which is subject to a non-negativity constraint: ${ }^{12}$

$$
\begin{aligned}
\max _{s, c_{1}, c_{2}, \hat{s}, z} U\left(c_{1}^{\prime}, c_{2}\right) & =\ln \left(c_{1}+\rho z\right)+\beta \ln c_{2} \quad \text { s.t. } \\
p_{1} c_{1}+p_{2} c_{2} & \leq w-s+R s+(R-q) \hat{s}-R z \\
p_{1} c_{1}+q \hat{s} & \leq w-s \\
0 & \leq z \leq s
\end{aligned}
$$

\footnotetext{
${ }^{11}$ The budget constraint implicitly includes the CIA for $t=2$ as the investor holds only cash when she enters the goods market in $t=2$.

${ }^{12}$ The Cobb-Douglas utility function (2) makes $c_{t}>0$ as long as $w>0$.
} 
Note that an investors' total consumption in $t=1, c_{1}^{\prime}$, is the sum of the consumption purchased via the goods market, $c_{1}$, and the real return from the possible liquidation of assets, $\rho z$. Solving the maximisation problem with the Lagrangian

$$
\begin{aligned}
\max _{s, c_{1}, c_{2}, \hat{s}, z} \Lambda & =\ln \left(c_{1}+\rho z\right)+\beta \ln c_{2} \\
& -\lambda\left[p_{1} c_{1}+p_{2} c_{2}-(w-s)-R s-(R-q) \hat{s}\right] \\
& -\mu\left[p_{1} c_{1}+q \hat{s}-(w-s)\right]
\end{aligned}
$$

yields as first-order conditions

$$
\begin{array}{lll}
\frac{d \Lambda}{d c_{1}}=\frac{1}{c_{1}+\rho z}-\lambda p_{1}-\mu p_{1}=0 & \longrightarrow & \mu+\lambda=\frac{1}{p_{1}\left(c_{1}+\rho z\right)} \\
\frac{d \Lambda}{d c_{2}}=\frac{\beta}{c_{2}}-\lambda p_{2}=0 & \longrightarrow \quad \lambda=\frac{\beta}{p_{2} c_{2}} \\
\frac{d \Lambda}{d s}=-\lambda+\lambda R-\mu=0 & \longrightarrow \mu=\lambda(R-1) \\
\frac{d \Lambda}{d \hat{s}}=\lambda(R-q)-\mu q=0 & \longrightarrow \mu=\lambda\left(\frac{R}{q}-1\right) \\
\frac{d \Lambda}{d z}=\frac{1}{c_{1}+\rho z} \rho-\lambda R \leq 0 & \\
\frac{d \Lambda}{d \lambda}=-p_{1} c_{1}-p_{2} c_{2}+(w-s)+R s+(R-q) \hat{s} \geq 0 \\
\frac{d \Lambda}{d \mu}=-p_{1} c_{1}-q \hat{s}+(w-s) \geq 0
\end{array}
$$

and $\frac{d L}{d z} z=0, \frac{d L}{d \lambda} \lambda=0$ and $\frac{d L}{d \mu} \mu=0$ as complementary slackness conditions. ${ }^{13}$ Since the costly liquidation is inefficient for $p_{1} \rho<1$, investors will not use it under certainty, and $z=0 .{ }^{14}$ As will become clear from the discussion of the goods market in the next section, the price of goods $p_{1}$ equals its expected value, i.e. $p_{1}=1$, under certainty, so $\rho<1$ is a necessary and sufficient condition for $z=0$.

(4c) and (4d) show that $q=1$ in the equilibrium under certainty because holding money would be dominated from $t=0$ to $t=1$ for $q>1$ and $s=w$, while holding shares would be dominated from $t=0$ to $t=1$ for $q<1$ and $s=0$. For $q=1$, money and shares are equivalent assets from $t=0$ to $t=1$. Since money is dominated by shares over the long run, the CIA is binding in $t=1 .^{15}$

\footnotetext{
${ }^{13}$ The second-order conditions for a maximum are fulfilled, since (3) maximises a strictly concave utility function under linear constraints and the optimum is an interior solution.

${ }^{14}$ By plugging $\mu$ from (4c) in (4a), solving for $\lambda$ and then plugging $\lambda$ in the inequality (4e), it can be shown that $d \Lambda / d z$ is negative and thus $z=0$ as long as $p_{1} \rho<1$.

${ }^{15}$ Since $R>1$ by assumption and $\lambda>0$ from (4b), the FOC for optimal investment in $s$ yields $\mu>0$.
} 
The only possible symmetric equilibrium is $\hat{s}=0$, i.e. there is no trade on the asset market in $t=1$, and money is only held for consumption in $t=1$ : (4g) reduces to $p_{1} c_{1}=w-s$. The combination of (4a) and (4b) shows that a binding CIA drives a wedge $\mu$, the marginal utility of cash's liquidity services, between the marginal utilities of consumption in $t=1$ and $t=2:{ }^{16}$

$$
\mu+\frac{\beta}{p_{2} c_{2}}=\frac{1}{p_{1} c_{1}} .
$$

According to (4c), the wedge $\mu$ equals the marginal utility of wealth, $\lambda$, times the excess return of shares over money, $R-1$, such that the marginal rate of intertemporal substitution equals the price ratio times the return on shares:

$$
\frac{c_{2}}{\beta c_{1}}=\frac{p_{1}}{p_{2}} R \text {. }
$$

Given the optimal consumption in $t=1$ and 2, the budget constraint (4f) and the CIA (4g), the optimal investment decision in $t=0$ is

$$
\begin{aligned}
s & =\frac{\beta}{1+\beta} w \quad \text { and } \\
m & =\frac{1}{1+\beta} w .
\end{aligned}
$$

An individual investor has consumption demands of ${ }^{17}$

$$
\begin{aligned}
& c_{1}=\frac{w}{(1+\beta) p_{1}} \text { and } \\
& c_{2}=\frac{\beta R w}{(1+\beta) p_{2}} .
\end{aligned}
$$

Finally, the investment and consumption decisions of individual investors $i$ can be aggregated to aggregate investment and consumption. Let capital letters denote aggregate values of the respective variable, i.e. $W \equiv \int_{i \in I} w d i, M \equiv$ $\int_{i \in I} m d i, S \equiv \int_{i \in I} s d i, C_{1} \equiv \int_{i \in I} c_{1} d i$ and $C_{2} \equiv \int_{i \in I} c_{2} d i$. Given $I=[0 ; 1]$, the following Proposition 1 summarises the situation under certainty:

Proposition 1 In the symmetric equilibrium under certainty, investors split their wealth in money $\left(M=\frac{1}{1+\beta} W\right)$ and shares $\left(S=\frac{\beta}{1+\beta} W\right)$ and consume $C_{1}=\frac{1}{p_{1}(1+\beta)} W$ and $C_{2}=\frac{\beta R}{p_{2}(1+\beta)} W$. The asset price $q=1$ and no assets are traded in the symmetric equilibrium.

Plugging $R=1 / \beta$ into the results of Proposition 1 yields a special result:

\footnotetext{
${ }^{16}$ Note that $\mu \geq 0$ represents the standard complementary slackness condition: If the CIA is not binding $(\mu=0)$, the marginal utility of money's liquidity services is zero; but if the marginal utility of money's liquidity services is positive, the liquidity constraint becomes binding $(\mu>0)$.

${ }^{17}$ For completeness, the Lagrangian parameters are $\lambda=\frac{1+\beta}{R w}$ and $\mu=\lambda(R-1)$.
} 
Corollary 1 If the interest rate $R$ equals the discount rate $1 / \beta$, investors spend the same amount of money in both periods, i.e. $p_{1} C_{1}=p_{2} C_{2}$, and consume the same amount of goods, i.e. $C_{1}=C_{2}$, if prices remain constant.

To concentrate on the intertemporal substitution effects of liquidity preference shocks, I start from the situation in Corollary 1 with perfect consumption smoothing and thus assume $\beta R=1$ where useful below.

\subsubsection{Goods production and goods market}

Because I want to focus on events on the asset market, in particular on the effects of emergency liquidity provision by the central bank in section 3, and the direct spillover effects to the goods market, the model includes a very stylised version of a goods market. Non-storable goods are produced by a mass of 1 of identical competitive firms at the beginning of periods $t=1,2$ with total labour input $N_{t}=\bar{N}$ from identical workers who cannot participate on the asset market and capital input $K_{t}$ according to a Cobb-Douglas production function

$$
Y_{t}=K_{t}^{\alpha} \bar{N}^{1-\alpha}
$$

with $0<\alpha<1$. Trade on the goods market takes place after the realisation of the liquidity shock for investors and after trade on the asset market. While aggregate supply is already produced and thus fixed at $Y_{t}$, aggregate demand consists of demand from workers based on their nominal labour income $\psi_{t}$ and from investors as derived in the previous section.

Given a Cobb-Douglas production function with constant returns to scale and perfect competition, the Euler theorem states that production factors are paid their marginal product times the respective factor input. With the production function (5), workers should receive the share of total output $Y_{t}$ that reflects their relative importance in production as captured by $1-\alpha$, while capital owners should receive $\alpha Y_{t}$. Furthermore, I assume that investors' demand $C_{t}$ represents the whole factor income of capital, such that $C_{t}=\alpha Y_{t}$ and that the real investment $S$ determines the constant producible aggregate real supply $\bar{Y}$ with $\partial \bar{Y} / \partial K \cdot d K / d S>0 .^{18}$

Since I have a model in nominal units, labour income for period $t$ is determined in nominal wage negotiations between workers and firms ${ }^{19}$ at the end of period $t-1$ such that their expected real income is $\Psi_{t}=(1-\alpha) Y_{t}$. Hence, the agreed nominal wage is $\psi_{t}=\Psi_{t} E_{t-1}\left[p_{t}\right]=(1-\alpha) Y_{t} E_{t-1}\left[p_{t}\right]$ given the

\footnotetext{
${ }^{18}$ Although this is an obvious departure from a full general equilibrium model where the income from capital is directly linked to the marginal product of capital, the crucial effects of the model should still hold in general equilibrium under the assumption of a cash-in-advance constraint for investors and limited asset market participation.

${ }^{19}$ Firms only produce consumption goods and negotiate wages in the model.
} 
expected price level $E_{t-1}\left[p_{t}\right] . E_{0}\left[p_{1}\right]$ is normalised to $1 .^{20}$ For simplicity, I assume that workers build their price expectations based on the quantity equation, i.e. they expect that investors use all their available nominal funds for the purchase of consumption goods in the respective period. ${ }^{21}$ Hence, money holdings $M=W-S=E_{0}\left[p_{1} C_{1}\right]$ and the supply of goods $\bar{Y}$ represent the information set for the wage negotiations in $t=0$. The nominal return from the investment $R S$ plus any unused $M$ from $t=1$ equal $E_{1}\left[p_{2} C_{2}\right]$. Together with $Y_{2}^{s}$, this provides the information for the negotiations in $t=1$. The expected nominal demand $E_{t-1}\left[p_{t} C_{t}\right]$ in turn has to be equal to the expected income share of capital, $E_{t-1}\left[p_{t}\right] \alpha Y_{t}$. Due to the normalisation $E_{0}\left[p_{1}\right]=1, C_{1}=\alpha \bar{Y} .{ }^{22}$ Under certainty, this also means that $E_{1}\left[p_{2}\right]=p_{2}=1$ as well if $\beta R=1$ because the CIA binds $(\mu>0)$ and investors transfer no money to $t=2$. Hence, investors' nominal funds are thus identical in $t=1$ and 2 . If $\beta R \neq 1$, investors' nominal funds differ in both periods under certainty. The nominal wage negotiations in $t=1$ determine $\psi_{2}$ such that the price $p_{2}$ adjusts such that workers receive $1-\alpha$ and investors $\alpha$ of the constant aggregate supply $\bar{Y}$ in $t=2$. Hence, aggregate demand $Y_{t}^{d}$ and aggregate supply $Y_{t}^{s}$ are

$$
\begin{gathered}
Y_{t}^{d}=\frac{\psi_{t}}{p_{t}}+C_{t}=\Psi_{t}+C_{t} \text { and } \\
Y_{t}^{s}=\bar{Y} .
\end{gathered}
$$

To summarise the equilibrium on the goods market under certainty for $\beta R=1$, the expected price of goods $E_{t-1}\left[p_{t}\right]$ equals the actual price $p_{t}=1$ for $t=1,2$. Investors consume $C_{1}=C_{2}=W /(1+\beta)$, while total production equals $Y_{1}=$ $Y_{2}=W /[\alpha(1+\beta)]$ and workers consume $\frac{1-\alpha}{\alpha}$ times investors' consumption, i.e. $\Psi_{1}=\Psi_{2}=\frac{1-\alpha}{\alpha} W /(1+\beta)$.

\subsection{Aggregate Risk}

What is the efficient response to a positive aggregate demand shock in $t=$ 1? If the supply of goods can be adjusted to the increased demand, it will be increased until the marginal costs of doing so equal the marginal benefit. In this model, production takes place before the shock, so the liquidation technology offers the only way to increase supply in $t=1$. Since the liquidation costs are very high, investors will use it only for large shocks. In an intermediate range, prices adjust such that the marginal rate of intertemporal substitution equals

\footnotetext{
${ }^{20}$ This assumption avoids any problems with a possible indeterminacy of the price level.

${ }^{21}$ For example, Illing (1997) and Walsh (2003) model aggregate demand with a quantity equation.

${ }^{22}$ Actually, $C_{1}$ is determined by $W, S$ and $p_{1}$ (see table 2). With nominal $W$ and real $C_{1}=\alpha Y$ fixed, $p_{1}$ is no free parameter any more. But the link between $S$ and $K$ and thus $\bar{Y}$ could be normalised such that $E_{0}\left[p_{1}\right]=1$.
} 
the relative prices.

Since the optimal investment strategy in $t=0$ depends on expectations about developments on the asset and the goods market in $t=1$ and 2 , the model has to be solved by backward induction. Hence, the allocations on the goods market in $t=2$ and $t=1$ as well as the influence of the shocks on the optimal behaviour of investors on the asset market in $t=1$ have to be taken into account when one solves the utility maximisation problem of investors in $t=0$. For illustrative purposes, however, it will be easier to begin with the description of the asset market, turn to the goods market afterwards and then solve the initial investment problem given the behaviour in $t=1,2$.

\subsubsection{Asset market}

The optimal investment decision problem for an individual investor under aggregate risk becomes

$$
\begin{aligned}
\max _{s, c_{1}, c_{2}, \hat{s}, z} E\left[U\left(c_{1}^{\prime}, c_{2}\right)\right] & =\int_{-\infty}^{\infty}\left(\gamma \ln \left(c_{1}+\rho z\right)+\beta \ln c_{2}\right) f(\gamma) d \gamma \quad \text { s.t. } \\
p_{1} c_{1}+p_{2} c_{2} & \leq w-s+R s+(R-q) \hat{s}-R z \\
p_{1} c_{1}+q \hat{s} & \leq w-s \\
0 & \leq z \leq s .
\end{aligned}
$$

The solution to this maximisation problem in section A of the appendix uses the Leibniz-Rule and yields as first order conditions

$$
\begin{aligned}
& \frac{\partial \Lambda}{\partial c_{1}}=\frac{\gamma}{c_{1}+\rho z}-\lambda p_{1}-\mu p_{1}=0 \\
& \frac{\partial \Lambda}{\partial c_{2}}=\frac{\beta}{c_{2}}-\lambda p_{2}=0 \\
& \frac{\partial \Lambda}{\partial \hat{s}}=\lambda(R-q)-\mu q=0 \\
& \frac{\partial \Lambda}{\partial z}=\frac{\gamma}{c_{1}+\rho z} \rho-\lambda R \leq 0 \\
& \frac{\partial \Lambda}{\partial \lambda}=-p_{1} c_{1}-p_{2} c_{2}+w+(R-1) s+(R-q) \hat{s}-R z \geq 0 \\
& \frac{\partial \Lambda}{\partial \mu}=-p_{1} c_{1}-q \hat{s}+w-s \geq 0 \\
& \frac{d \Lambda}{d s}=\int_{-\infty}^{\infty}[\lambda(R-1)-\mu] f(\gamma) d \gamma=0 .
\end{aligned}
$$

and $\frac{\partial \Lambda}{\partial z} z=0, \frac{\partial \Lambda}{\partial \lambda} \lambda=0$ and $\frac{\partial \Lambda}{\partial \mu} \mu=0$ as complementary slackness conditions. ${ }^{23}$

\footnotetext{
${ }^{23}$ As for the maximisation problem (3) under certainty, the second-order conditions for a maximum are fulfilled since (8) maximises a strictly concave utility function under linear constraints
} 
Since all investors are identical without idiosyncratic risk, they all want to sell or buy assets in response to an aggregate liquidity shock $\gamma$ at the same time in $t=1$ in order to adjust their money holdings optimally to their desired consumption which is subject to the CIA. As the aggregate stock of assets is determined in $t=0$, however, they cannot sell or buy in the aggregate. Hence, the asset price $q$ has to adjust to exclude any excess demand or supply of assets, i.e. market clearing in $t=1$ requires that $\hat{S}=\int_{i \in I} \hat{s} d i=0$.

Depending on the realisation of the liquidity shock $\gamma$, the asset price $q$, the Lagrangian parameters $\lambda$ and $\mu$ and the choice variables $c_{1}, c_{2}$ and $z$ lie in three different ranges. For $\gamma<\frac{\beta(W-S)}{R S} \equiv C I A$, investors want to transfer wealth into the next period. This drives up the asset price $q$, which is bounded by $R$ : Nobody would be willing to pay more for the asset than the asset's fixed payoff in the next period. In this case, the CIA becomes non-binding $(\mu=0)$.

For greater values of $\gamma$, however, the CIA is binding and the asset price depends on the cash in the market as in Allen and Gale (1994, 2005). As long as investors do not liquidate their assets, the asset price captures the full effect of $\gamma \in\left[\frac{\beta(W-S)}{R S} ; \frac{\beta(W-S)}{p_{1} \rho S}\right]$. For sufficiently large liquidity shocks $\gamma>\frac{\beta(W-S)}{p_{1} \rho S} \equiv$ $L I Q$, the asset price $q$ falls to a level where the investors become indifferent between liquidating the asset and selling the asset. Since they cannot sell in the aggregate, they costly liquidate part of their assets $(z>0)$. Table 2 summarises the equilibrium values of the relevant variables in the three ranges of $\gamma \cdot{ }^{24}$ Figure 4 illustrates the asset price $q$ and the two Lagrangian parameters on the budget constraint and the CIA as a function of $\gamma$ for $R=1 / \beta=1.1, W=$ $1, S=\frac{\beta}{1+\beta} W, \rho=0.7$. The possibility of a severe drop in $q$ captures the microeconomic view of liquidity, as an illiquid asset cannot be sold quickly without costs.

Turning to the optimal investment decision in $t=0$, the first-order condition for optimal investment in the asset is given by equation $(9 \mathrm{~g})$. Using the results for $\lambda$ and $\mu$ from table 2 and the definitions of the cumulative distribution function $F(x) \equiv \int_{-\infty}^{x} f(\gamma) d \gamma$ of the liquidity shock $\gamma$ and the function $G(x) \equiv \int_{-\infty}^{x} \gamma f(\gamma) d \gamma$, section A in the appendix shows that the determination of the optimal investment $s$ requires an explicit parameterisation of the shock's density function $f(\gamma)$. I assume $\gamma$ to be uniformly distributed between $a$ and $b$ with $0<a<b$. Table 3 summarises the information which is derived in the appendix.

There is only one variable left that depends on the realisation of $\gamma$, namely the

and the optimum is an interior solution.

${ }^{24}$ Note that the Cobb-Douglas preferences (2) determine the relative expenditures $p_{1} c_{1}$ to $p_{2} c_{2}$ such that $c_{1}$ is independent from $p_{2}$ and $c_{2}$ is independent from $p_{1}$ in general. Only for $\gamma>L I Q$ and thus $z>0, c_{2}$ depends on $p_{1} \rho$ because this is the nominal value of liquidation in $t=1$. Without central bank intervention, $p_{1}=1$ in this case as demonstrated the next section 2.3.2. 
Table 2: Summary of the values of the asset price q, the Lagrangian parameters $\lambda$ and $\mu$ and the choice variables $c_{1}, c_{2}$ and $z$ after the realisation of $\gamma$ in $t=1$.

\begin{tabular}{l|c|c|c}
\hline \hline & $\gamma<\frac{\beta(W-S)}{R S} \equiv C I A$ & $\frac{\beta(W-S)}{R S} \leq \gamma \leq \frac{\beta(W-S)}{p_{1} \rho S}$ & $\gamma>\frac{\beta(W-S)}{p_{1} \rho S} \equiv L I Q$ \\
\hline$q$ & $R$ & $\frac{\beta(W-S)}{\gamma S}$ & $p_{1} \rho$ \\
$\lambda$ & $\frac{\beta+\gamma}{w-s+R s}$ & $\frac{\beta(W-S+R S)}{R S(w-s+R s)}$ & $\frac{p_{1} \rho(\beta+\gamma)}{R\left(w-s+p_{1} \rho s\right)}$ \\
$\mu$ & 0 & $\lambda\left(\frac{\gamma R S}{\beta(W-S)}-1\right)$ & $\lambda\left(\frac{R}{p_{1} \rho}-1\right)$ \\
$z$ & 0 & 0 & $\frac{\gamma p_{1} \rho s-\beta(w-s)}{p_{1} \rho(\beta+\gamma)}$ \\
$c_{1}$ & $\frac{\gamma}{p_{1}(\beta+\gamma)}(w-s+R s)$ & $\frac{w-s}{p_{1}}$ & $\frac{w-s}{p_{1}}$ \\
$c_{2}$ & $\frac{\beta}{p_{2}(\beta+\gamma)}(w-s+R s)$ & $\frac{R s}{p_{2}}$ & $\frac{\beta R\left(w-s+p_{1} \rho s\right)}{p_{2} p_{1} \rho(\beta+\gamma)}$ \\
\hline \hline
\end{tabular}

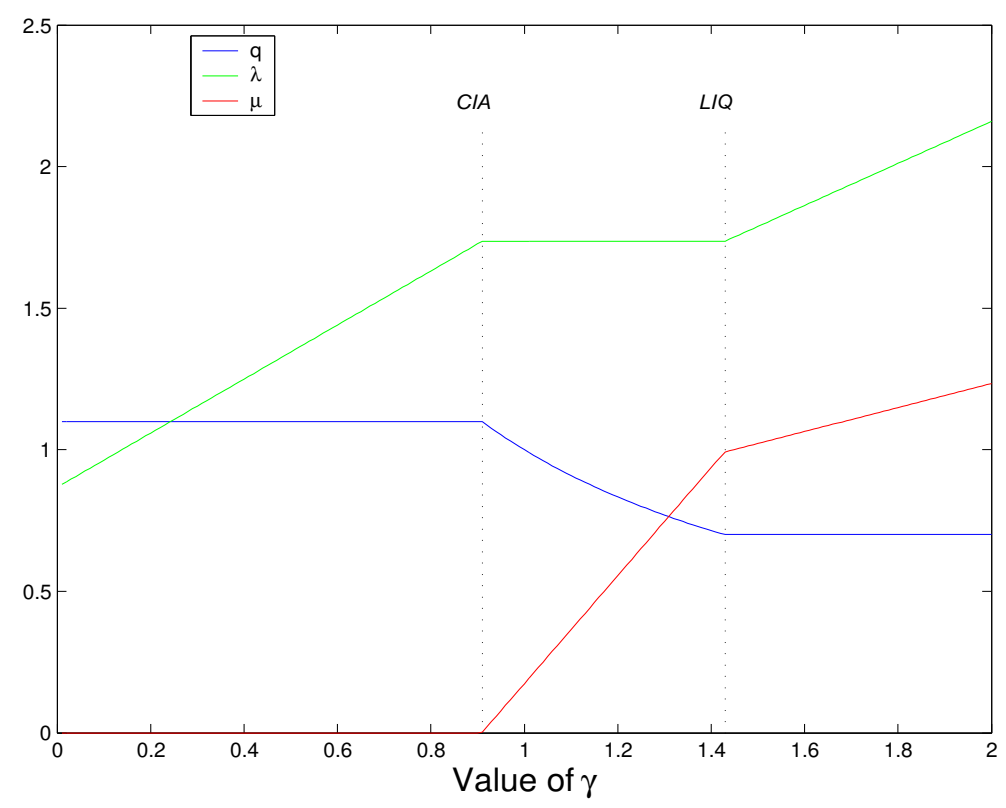

Figure 4: $q, \lambda, \mu$ as a function of $\gamma$ and given different parameter values. 
Table 3: Summary of $f(\gamma), F(\gamma), G(\gamma)$ in $t=1$.

\begin{tabular}{c|cc|cc}
\hline \hline & $\gamma \in[a ; b]$ & $\gamma \notin[a ; b]$ & $\gamma=C I A$ & $\gamma=L I Q$ \\
\hline$f(\gamma)$ & $\frac{1}{b-a}$ & 0 & $\frac{1}{b-a}$ & $\frac{1}{b-a}$ \\
$F(\gamma)$ & $\frac{\gamma-a}{b-a}$ & 0 & $\frac{\frac{\beta(W-S)}{b-a}-a}{\frac{\beta(W-S)}{p_{1} \rho}-a}$ \\
$G-a$ & $F(C I A) \cdot$ & $F(L I Q) \cdot$ \\
$G(\gamma)$ & $\frac{\gamma-a}{b-a} \cdot \frac{1}{2}(\gamma+a)$ & 0 & $\frac{1}{2}\left(\frac{\beta(W-S)}{R S}+a\right)$ & $\frac{1}{2}\left(\frac{\beta(W-S)}{p_{1} \rho S}+a\right)$ \\
\hline \hline
\end{tabular}

goods price $p_{1}$, which is determined on the goods market as described in the following section. As noted above, however, the utility function (2) implies that $p_{1}$ only matters for $\lambda, \mu, C_{t}$ in the range $\gamma \geq \frac{\beta(W-S)}{p_{1} \rho S}$. Table 2 shows that in this range investors use all their nominal funds $w-s$ to buy consumption goods on the goods market. The detailed description of the goods market in the next section 2.3.2 shows that $p_{1}=1$ in this case. Given this information, one can now solve for the optimal investment in the asset $s$.

Figure 5 illustrates that the optimal investment is decreasing in the standard deviation of $\gamma, \sigma(\gamma)=\frac{b-a}{2 \sqrt{3}}$, while this effect is more pronounced for a lower real payoff of the liquidation technology $\rho$. Without aggregate risk, proposition 1 states that investors hold $S=\frac{\beta}{1+\beta} W \approx 0.4762$ for $R=1 / \beta=1.1$ and $W=1$. Initially, introducing aggregate risk does not affect $S$ because the asset price $q$ absorbs the full impact of the liquidity shock for the chosen parameter values, i.e. the CIA always binds $(F(C I A)=0)$ and no assets are liquidated $(F(L I Q)=1)$ given the equilibrium $S$. Further increasing $\sigma(\gamma)$ makes the risk-averse investors reduce their investment $S$. As the real payoff of liquidations $Z$ increases in $\rho$ and the liquidation threshold $L I Q$ decreases in $S$, the reduction in $S$ caused by increased aggregate risk is dampened by a greater $\rho$ and the solid line $(\rho=0.9)$ lies above the dashed line $(\rho=0.5)$ in figure 5.

This is the solution of the model with aggregate risk and access to a costly real liquidation technology for investors. The analysis of an emergency liquidity assistance by the central bank requires at first a deeper discussion of the goods market in the next section. Furthermore, the costs and benefits of such an intervention need to be based on an explicit welfare function for the central bank. I turn to this issue in section 3. 


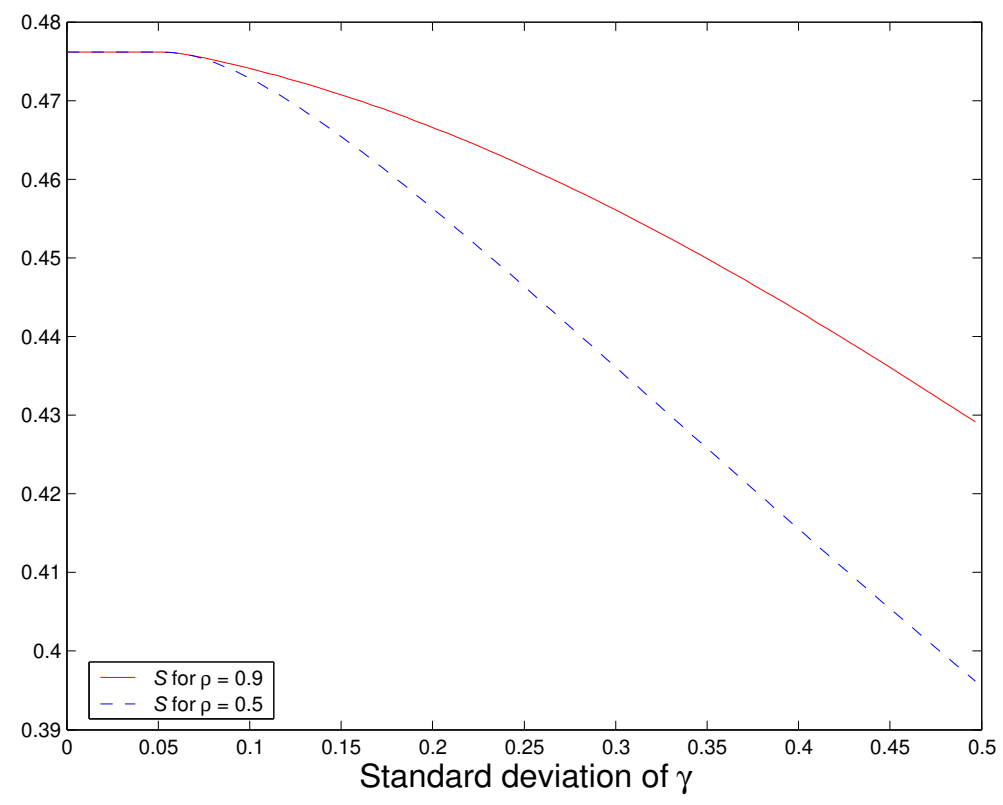

Figure 5: Optimal investment $S$ for $R=1 / \beta=1.1$ and $W=1$.

\subsubsection{Goods market}

Investors' liquidity shocks in $t=1$ can spill over to the goods market via a demand effect in $t=1$ and a supply effect in $t=2$. Let $\eta$ denote the first channel that links the asset market and the goods market: For small realisations of the liquidity shock $\gamma<C I A$, the CIA of investors becomes non-binding and they do not use all their money for consumption in $t=1$. This represents a negative nominal aggregate demand shock on the goods market, represented by $\eta<0$. If the liquidity shock $\gamma$ is in the range of $C I A \leq \gamma \leq L I Q$, the asset price $q$ absorbs the full effect of the liquidity shock as noted in the previous section and investors' nominal demand $p_{1} C_{1}=W-S$. For large liquidity shocks $\gamma>L I Q$, investors liquidate part of their assets and thus increase the total resources available for consumption in $t=1$ beyond $\bar{Y}$. Since investors satisfy $\rho Z$ of their desired consumption goods with the liquidation technology, they still demand $p_{1} C_{1}=W-S$ on the goods market. If, however, the central bank intervenes on the asset market and injects additional money in case of large realisations of $\gamma$ as will be shown in the following section 3, investors' nominal demand rises above the level expected in the wage negotiations. This is represented by a positive aggregate demand shock $\eta>0$.

The rest of aggregate demand depends on nominal labour income $\psi_{t}$, which is determined in nominal wage negotiations at $t-1$ as explained in section 2.2.2: 
Perfect competition and the Cobb-Douglas production function (5) require that workers can consume $(1-\alpha) Y_{t}$ in $t$ given the expected price level $E_{t-1}\left[p_{t}\right]$ which is normalised to 1 for $t=1$. Workers build their price expectations based on the quantity equation, i.e. they expect that the total amount of money held by investors at the time of the wage negotiations is spent in $t=1$. Hence, the expected nominal demand $E_{0}\left[p_{1} C_{1}\right]=W-S$ has to be equal to the expected capitalists' income share $E_{0}\left[p_{1}\right] \alpha Y_{t}=\alpha \bar{Y}$ as $E_{0}\left[p_{1}\right]=1 .^{25}$ Therefore, the aggregate demand relationship from equation (6) becomes

$$
Y_{1}^{d}=\frac{\psi_{1}+W-S+\eta}{p_{1}},
$$

while aggregate supply is again fixed to ${ }^{26}$

$$
Y_{1}^{s}=\bar{Y}
$$

Note that the price impact of nominal demand shocks $\eta$ originating from the asset market is less than 1 as $\psi_{1}$ is constant. Hence, the first channel that links the asset with the goods market, $\eta$, causes a redistribution effect from investors' consumption share at $p_{1}=1$ towards workers for $\eta<0$ and from workers towards investors for $\eta>0$. Given the determination of $E_{0}\left[p_{1}\right]$ described above, positive price shocks can only occur with additional money from the central bank which will be discussed extensively in the following section 3 .

The exercise of the real put option acquired with the asset $s$, i.e. the application of the costly liquidation technique, in response to large liquidity shocks $\gamma>L I Q$ with no or insufficient emergency liquidity assistance by the central bank causes the second link between the asset market and the goods market: Without costly liquidations, the capital stock $K_{t}$ is fixed over the time horizon of this model and aggregate output is $\bar{Y}$, given the initial investment $S$. If investors choose to liquidate part of their shares, i.e. $Z>0$, this liquidation takes place after production in $t=1$ and increases the real resources available for consumption in $t=1$, but reduces $K_{2}$. The lower capital input in $t=2$ lowers

\footnotetext{
${ }^{25}$ This assumption is a short-cut from the rational $E_{0}^{r a t}\left[p_{1} C_{1}\right]$ because investors will spend all their money in $t=1$ only as long as their CIA binds, i.e. $\gamma \geq C I A$, and less for $\gamma<C I A$. This implies $E_{0}^{\text {rat }}\left[C_{1}\right]<C_{1}(\gamma \geq C I A)$ and $E_{0}[\eta]<0$ without central bank intervention. Hence, workers get more than their expected share of aggregate supply $\bar{Y}$ in $t=1$ on average and are thus implicitly compensated for their real income risk in $t=1$. To summarise, the way workers form their expectations and the normalisation of $E_{0}\left[p_{1}\right]$ determine the size of the redistribution effect of investors' nominal demand on workers after the realisation of $\gamma$, but not the possibility of such redistributions.

${ }^{26} \bar{Y}$ may be different from the one under certainty, however, since it depends on $S$ which may decrease with the extent of aggregate risk as demonstrated in figure 5.
} 
$\bar{Y}$ by $\Delta(Z)$, with $\frac{d \Delta}{d Z}>0$, and aggregate supply becomes

$$
Y_{2}^{s}=\bar{Y}-\Delta(Z)
$$

Any risk has disappeared from the model at the time of the nominal wage negotiations for $t=2$. Workers build their price expectations $E_{1}\left[p_{2}\right]$ based on investors' safe nominal revenues $R(S-Z)$, potentially unused money holdings $W-S-p_{1} C_{1}$ and the known $Y_{2}^{s}$. Again, perfect competition allows them to consume $\Psi_{2}=(1-\alpha) Y_{2}$, which implies a nominal wage of $\psi_{2}=$ $E_{1}\left[p_{2}\right](1-\alpha) Y_{2} \cdot{ }^{27}$ The aggregate demand equation for $t=2$ then is

$$
Y_{2}^{d}=\frac{\psi_{2}+R(S-Z)+W-S-p_{1} C_{1}}{p_{2}} .
$$

and equals aggregate supply at $p_{2}=E_{1}\left[p_{2}\right]$ in equilibrium:

$$
\Psi_{2}+C_{2}=\bar{Y}-\Delta(Z)
$$

$p_{2}$ and its expected value adjust relative to $p_{1}$ such that investors' real consumption $C_{2}=\alpha[\bar{Y}-\Delta(Z)]$. For example, if investors' liquidity shock $\gamma$ is within the intermediate range $C I A<\gamma<L I Q$, the CIA is binding and $W-S=p_{1} C_{1}$, but no assets are liquidated, i.e. $Z=0$. (12) reduces to

$$
Y_{2}^{d}=\frac{\psi_{2}+R S}{p_{2}}
$$

and $p_{2}=p_{1}=1$ for $\beta R=1$ and a sufficiently small variance of $\gamma$ that leaves $S=\beta /(1+\beta) W$ from the certainty case unaffected (see also figure 5). Since investors' Cobb-Douglas-preferences smooth nominal expenditures over $t=1$ and $2, p_{2}$ has no effect on investors' behaviour in $t=1$ given $S$.

To summarise, the two direct channels that link the asset market to the goods market in this model are the aggregate demand shock $\eta$ in period 1 and the aggregate supply shock $\Delta$ in period 2, which both depend on the realisation of the liquidity shock $\gamma$ in $t=1$.

\footnotetext{
${ }^{27}$ Note again that investors do not react to possible changes of $p_{2}$ relative to a constant $p_{1}$ because the Cobb-Douglas-preferences determine the expenditure share rather than real consumption in each period. Hence, given the constant produceable aggregate supply $\bar{Y}$ and workers' desired income of $(1-\alpha) Y_{2}, p_{2}$ would have to deviate from $p_{1}$ even if $\gamma=E_{0}[\gamma]=1$ for example if $\beta R \neq 1$ in order to equate investors' intertemporal rate of substitution to the relative price $p_{1} / p_{2}$ for constant real consumption $C_{2}=C_{1}=\alpha \bar{Y}$.
} 


\section{Central bank intervention}

\subsection{Welfare function}

The direct spillover effects from the asset market to the goods market mean that the central bank may intervene on the asset market even if it does not take investors' welfare into account. The loss function $\mathcal{L}$ of the central bank consists of the weighted sum of two parts: The increase of $p_{1}$ above the desired price level $p_{1}^{*}$ because of the associated real income loss of workers and the deviation of aggregate supply $Y_{2}^{s}$ from $\bar{Y}$ caused by liquidations $Z, \Delta(Z)::^{28}$

$$
\mathcal{L}=\left(p_{1}-p_{1}^{*}\right)-\omega\left(Y_{2}^{s}-\bar{Y}\right)
$$

$\omega$ reflects the weight on the real income loss of workers in $t=2$ relative to the weight on the real income loss of workers in $t=1$ caused by a rise in $p_{1}$ and thus implicitly includes the central bank's time discount factor. Let $p_{1}^{*}$ be normalised to 1 and thus equal the expected price level $E_{0}\left[p_{1}\right]$. It is sufficient to concentrate on $p_{1}$ and $Y_{2}^{s}$ in this stylised model because $Y_{1}^{s}$ is produced before any shocks occur and thus not directly influencable by monetary policy under discretion ${ }^{29}$ and nominal wage negotiations for $t=2$ take place after any shocks and determine $p_{2}$ such that workers receive $\Psi_{t}=(1-\alpha) Y_{2}^{s}$.

The concentration on goods markets can be justified with several arguments: From a positive perspective because price stability and - differently accentuated - output stability are the mandate of most central banks in the world, where price stability is generally interpreted as a low but positive growth rate of some form of a consumer price index. From a political economy perspective, since people living mainly from their nominal labour income represent the majority of voters in a society and, as I show in this paper, this focus may even improve the welfare of investors as well. Finally, also from a normative perspective within the New Keynesian framework as argued by Woodford (2003) because asset prices are in general a lot more flexible than goods prices and the monetary authority should focus on a measure of relatively sticky core inflation to limit the distortions caused by nominal rigidities. ${ }^{30}$

\footnotetext{
${ }^{28}$ The discussion below shows that the central bank cannot intervene symmetrically in this model. Hence, the linear loss function represents a useful simplification. The results of the model are robust to a loss function that is quadratic in inflation and output deviations from their respective targets, but the comparative static analysis and the restrictions on some parameter values become more complex (see section B in the appendix).

${ }^{29}$ The indirect effect of central bank intervention on aggregate supply will be analysed in section 3.5. Section 3.6 discusses how optimal monetary policy can take the indirect effect into account.

${ }^{30}$ Note, however, that the normative argument has been subject of a long discussion in macroeconomics that goes far beyond the scope of this paper. For example, Woodford's argument neglects the information content of asset prices about future consumer price inflation that was emphasised by Alchian and Klein (1973). These authors concluded that asset prices should receive a very high
} 


\subsection{Asset market}

The central bank has the possibility to prevent the costly liquidation of shares if it acts as a lender or rather liquidity provider of last resort to the financial market. That means, it can enter repurchasing agreements with investors at a price (just) high enough to prevent liquidations and thus provide extra liquidity to the market. In such an emergency repurchasing agreement, the central bank buys $l$ assets at a nominal price $q$ and sells them to the same investor in $t=2$ for the asset's nominal payoff $R$. The total amount $L \equiv \int_{i \in I} l d i$ of assets bought, their buying price $q$ and thus the liquidity costs for investors $(R-\underline{q}) L$ all depend on the preferences of the central bank in (13). ${ }^{31}$ As in section 2.3, I begin with the asset market and an investors' optimal behaviour.

The possibility of a central bank intervention alters the optimal investment decision problem for an individual investor. The maximisation problem (8) under aggregate risk becomes

$$
\begin{aligned}
\max _{s, c_{1}, c_{2}, \hat{s}, z, l} E\left[U\left(c_{1}^{\prime}, c_{2}\right)\right] & =\int_{-\infty}^{\infty}\left(\gamma \ln \left(c_{1}+\rho z\right)+\beta \ln c_{2}\right) f(\gamma) d \gamma \quad \text { s.t. } \\
p_{1} c_{1}+p_{2} c_{2} & \leq w-s+R s+(R-q) \hat{s}-R z-(R-\underline{q}) l \\
p_{1} c_{1}+q \hat{s} & \leq w-s+\underline{q} l \\
0 & \leq z \leq s ; 0 \leq l \leq s ; l+z \leq s .
\end{aligned}
$$

The problem (14) is solved as in section 2.3.1. While the first-order conditions (9a) to $(9 \mathrm{~d})$ and $(9 \mathrm{~g})$ remain unchanged, the derivatives with respect to the Lagrangian parameters (9e) and (9f) become

$$
\begin{aligned}
& \frac{\partial \Lambda}{\partial \lambda}=-p_{1} c_{1}-p_{2} c_{2}+w+(R-1) s+(R-q) \hat{s}-R z-(R-\underline{q}) l \geq 0 \\
& \frac{\partial \Lambda}{\partial \mu}=-p_{1} c_{1}-q \hat{s}+w-s+\underline{q} l \geq 0
\end{aligned}
$$

weight in the price index that the central bank tries to stabilise; their argument was rejected mostly for practical reasons (see Cecchetti, Genberg, Lipsky and Wadhwani (2000), for example).

The modern discussion rather ranges between Bernanke and Gertler (1999), who argue that asset price changes are only relevant for monetary policy insofar as they change the forecasts of consumer price inflation and output, while Cecchetti et al. (2000) favour a more direct response to asset prices because this should limit the extent of asset price bubbles and thus dampen the volatility of output and inflation. The discussion below shows that the spillover effects from the asset to the goods market justify a direct monetary policy response to asset prices even if the central bank neglects the welfare of asset holders and there are no bubbles.

${ }^{31}$ The individual costs of emergency liquidity provision $(R-\underline{q}) l$ represent a deadweight loss in the model. Actually, these costs equal the nominal seigniorage income for the central bank. Section 3.6 includes a discussion of the optimal use of this seigniorage income. 
and the new first-order condition

$$
\frac{\partial \Lambda}{\partial l}=-\lambda(R-\underline{q})+\mu \underline{q} \leq 0, \quad l \geq 0
$$

is added to the system.

In order to limit the increase of the price level on the goods market $p_{1}$ caused by the extra liquidity in the market, the central bank will provide this liquidity at the highest cost for investors that still prevent the costly liquidation, i.e. $q$ is as low as possible. Since (16) implies that $\lambda\left(\frac{R}{q}-1\right)=\mu$ for $l>0$, it is obvious from (9c) that $q=q$ in equilibrium in this case. At the same time, the discussion in section 2.3.1 shows that $\lambda\left(\frac{R}{p_{1} \rho}-1\right)=\mu$ for $z>0$, i.e. $\gamma>L I Q . \underline{q}=p_{1} \rho=q$ causes investors' indifference between consuming by liquidating assets $(z>0)$ or by buying $c_{1}$ for $p_{1}$ on the goods market with cash from selling the asset at $\underline{q}$ to the central bank or at $q$ on the asset market. Hence, $\underline{q}=p_{1} \rho$ is the lowest price at which the central bank can prevent costly liquidations in response to large liquidity shocks $\gamma$.

\subsection{Goods market}

A closer look at the goods market in $t=1$ and 2 illuminates the mechanism of the model and the trade-off the central bank faces. In particular, the central bank needs to quantify the costs and benefits of additional liquidity to determine the optimal amount of nominal aggregate liquidity provision.

As in section 2.3.2, the aggregate demand shock $\eta$ in (10) can be negative in $t=1$, as investors transfer money into $t=2$ for $\gamma<C I A$. Due to the central bank intervention, however, $\eta$ can also be positive. For $\gamma>L I Q$, the central bank increases the amount of money available for consumption purchases in the economy by $q L$. Since aggregate supply is already produced at the beginning of $t=1$, the additional nominal funds $\underline{q} L$ cause a rise in the price of goods $p_{1}$ by $\tau q L .^{32}$ Given workers' fixed nominal wage $\psi_{1}$, this price increase reduces workers' real consumption $\Psi_{1}$ and increases the amount of goods investors can buy on the goods market with money. Investors' total consumption $C_{1}^{\prime}$ is then the sum of goods bought on the goods market $C_{1}$ with initial money holdings plus the liquidity provision $q L$ and the proceeds from the real liquidation $\rho Z$ that the central bank optimally admits. Crucially, once the nominal wage $\psi$ is fixed based on the expected nominal demand such that workers expect to receive $(1-\alpha) \bar{Y}$, a liquidity provision by the central bank that exceeds workers' expectations, independent of their expectation formation mechanism, will

\footnotetext{
${ }^{32}$ Using the parameters and variables of the model, the price impact can be expressed as $\tau=$ $\alpha p_{1} \rho /(W-S)$. To simplify the exposition of the arguments, I continue to use $\tau$ for the price impact of $L$.
} 
always induce this redistribution effect and increase the amount of real funds available for investors' consumption in $t=1$.

At the same time, the real liquidation of $Z$ assets causes a reduction of aggregate supply in $t=2$ by $\Delta(Z)=\kappa Z .{ }^{33}$ As the central bank intervention reduces the amount of liquidations by $L$, it increases $Y_{2}^{s}$ proportionately by $\kappa L$. Hence, aggregate supply $Y_{2}^{s}=\bar{Y}-\kappa Z$, where $Z$ denotes the amount of optimally admitted liquidations, and the aggregate demand equation (12) becomes

$$
Y_{2}^{d}=\frac{\psi_{2}+R(S-Z-L)+W-S-p_{1} C_{1}}{p_{2}} .
$$

Since any risk in the model is dissolved by the time of the wage negotiations for $t=2$, the nominal wage $\psi_{2}$ guarantees a real consumption of $\Psi_{2}=$ $(1-\alpha)(\bar{Y}-\kappa Z)$ and $E_{1}\left[p_{2}\right]=p_{2}$. As in section 2.3.2, $p_{2}=p_{1}=1$, if $\gamma \in$ $[C I A, L I Q], \beta R=1$ and $S=\beta /(1+\beta) W$, for example.

\subsection{Optimal central bank intervention}

The trade-off between the price impact $\tau$ and the output effect $\kappa$ determines the optimal amount of liquidity $L^{*}$ provided by the central bank. I define $Z^{*}$ as the aggregate amount of liquidated assets in response to a shock $\gamma$ in the absence of central bank intervention, i.e. $Z^{*} \equiv \int_{i \in I} z d i=\frac{\gamma p_{1} \rho S-\beta(W-S)}{p_{1} \rho(\beta+\gamma)}$ with $z=\frac{\gamma p_{1} \rho s-\beta(w-s)}{p_{1} \rho(\beta+\gamma)}$ taken from table 2 in section 2.3.1. The liquidation of $Z^{*}$ produces an output loss of $\kappa Z^{*}$ in $t=2$ with $\kappa>0$. An intervention of $L$ causes an increase in $p_{1}$ of $\tau \underline{q} L$ with $\tau>0$ above the expected price level $E_{0}\left[p_{1}\right]=1$. At the same time, it reduces the extent of costly liquidations $Z^{*}$ by $L$, which increases aggregate supply in $t=2$ by $\kappa L$. I assume $\omega \kappa>\rho \tau$ such that the value of the output gain is sufficiently high for a positive level of $L$ in response to large shocks $\gamma$. The endogeneity of the lowest intervention price $\underline{q}=p_{1} \rho$ implies that

$$
\begin{aligned}
& p_{1}=1+\tau \underline{q} L \\
\Leftrightarrow & p_{1}=1+\tau p_{1} \rho L \\
\Leftrightarrow & p_{1}=\frac{1}{1-\tau \rho L}
\end{aligned}
$$

\footnotetext{
${ }^{33}$ The linearity of the output loss serves again the purpose of expositional ease. Given the way the size of the economy $\bar{Y}$ is linked to the amount of assets $S, \kappa=R /\left(\alpha p_{2}\right)$.
} 
and requires $\tau \rho L<1$ for an equilibrium. Given this information about the price and output impacts of its intervention, the central bank optimises

$$
\begin{aligned}
\min _{L} \mathcal{L} & =\left(p_{1}-p_{1}^{*}\right)-\omega\left(Y_{2}^{s}-\bar{Y}\right) \\
& =\left(\frac{1}{1-\tau \rho L}-1\right)-\omega\left(\bar{Y}-\kappa\left(Z^{*}-L\right)-\bar{Y}\right) \\
& =\frac{\tau \rho L}{1-\tau \rho L}+\omega \kappa\left(\frac{\gamma S-\frac{\beta(W-S)(1-\tau \rho L)}{\rho}}{\beta+\gamma}-L\right) .
\end{aligned}
$$

In the optimum, the marginal costs of higher prices $p_{1}$ just equal the marginal benefit of greater output $Y_{2}^{s}$,

$$
\begin{gathered}
\frac{d \mathcal{L}}{d L}=\frac{\tau \rho}{(1-\tau \rho L)^{2}}+\omega \kappa\left(\frac{\beta(W-S) \tau}{\beta+\gamma}-1\right) \stackrel{!}{=} 0 \\
\Leftrightarrow \underbrace{\frac{\tau \rho}{(1-\tau \rho L)^{2}}}_{\text {direct marginal cost of } \frac{d p_{1}}{d L}}+\underbrace{\omega \kappa \frac{d p_{1}}{d L}}_{\text {indirect marginal cost of } \frac{\partial Y_{2}^{s}}{\partial Z^{*}} \cdot \frac{\partial Z^{*}}{\partial p_{1}}}=\underbrace{\omega \kappa}_{\text {marginal benefit of } \frac{\partial Y_{2}^{s}}{\partial L}} .
\end{gathered}
$$

Note that $\frac{d Z^{*}}{d L}>0$ since the goods price increase associated with $L>0$ makes the real liquidation technology more attractive. The optimal liquidity provision $L^{*}$ that fulfills the stability criterion $\tau \rho L<1$ is

$$
L^{*}=\frac{1}{\rho \tau}-\sqrt{\frac{\beta+\gamma}{\omega \kappa \tau \rho[\beta+\gamma-\beta(W-S) \tau]}} .
$$

Proposition 2 The optimal amount of assets purchased by the central bank $L^{*}$ increases in the size of the liquidity shock $\gamma$, the weight on the output gap $\omega$ and its marginal reduction of output losses $\kappa . L^{*}$ decreases in its marginal price impact $\tau$, the real payoff of the liquidation technology $\rho$ and the amount of money $W-S$ initially held by investors if $\omega \kappa>\rho \tau$ and $\gamma>L I Q$.

Proof. The derivatives of $L^{*}$ in equation (21) are positive with respect to $\gamma, \omega, \kappa$ and negative with respect to $\rho, \tau$ given the assumptions about the parameters.

Proposition 2 shows that the central bank will provide more liquidity in response to a greater shock $\gamma$ because it reduces the indirect marginal costs of intervening. ${ }^{34}$ The opposite is true for larger money holdings $W-S$ and more investment in the illiquid asset $S$ : More initial liquidity increases the marginal

\footnotetext{
${ }^{34}$ If the loss function (13) was quadratic in the output gap in $t=2$, also the marginal benefit of $L$ would increase with $Z^{*}$ and thus with $\gamma$ (see section B in the appendix).
} 
costs of $L$ as the same endogenous rise of $p_{1}$ raises the desired liquidations $Z^{*}$ by more. Furthermore, $L^{*}$ increases with the weight on output gap stabilisation relative to price stabilisation, $\omega$, because this makes an output loss due to liquidation more costly relative to a price increase due to central bank intervention. A greater output impact $\kappa$ of an intervention or a smaller price impact $\tau$ also improve the benefits of intervening relative to its costs and thus raise $L^{*}$. Finally, a greater $\rho$ amplifies the price impact of the necessary intervention ceteris paribus and thus lowers $L^{*}$.

A special situation arises if the central bank provides so much liquidity that $p_{1}$ rises until $p_{1} \rho=\underline{q}=R$. A further increase of $\underline{q}$ means that the central bank actually pays investors not to liquidate their assets and $\mu<0$ from (9c). But $\underline{q}>R$ may become necessary as it is the nominal value of the asset's real put option in $t=1, p_{1} \rho$, that determines $Z$, not the asset's final payoff $R$ (see table 2). This situation will not occur, however, as long as

$$
\begin{aligned}
p_{1} & <\frac{R}{\rho} \\
\Leftrightarrow \frac{1}{1-\tau \rho L^{*}} & <\frac{R}{\rho} .
\end{aligned}
$$

Taking $L^{*}$ from (21) and neglecting the indirect marginal costs of $L$ that reduce $L^{*}$ shows that

$$
\begin{aligned}
\frac{1}{1-\tau \rho\left(\frac{1}{\rho \tau}-\sqrt{\frac{1}{\omega \kappa \tau \rho}}\right)}<\frac{R}{\rho} \\
\Leftrightarrow R \sqrt{\frac{\tau}{\omega \kappa \rho}}>1
\end{aligned}
$$

is a sufficient condition for $p_{1}<\frac{R}{\rho}$ and thus $\underline{q}<R$.

\subsection{Welfare implications and the moral hazard effect}

How is the utility and the behaviour of investors affected by the central bank intervention? First, the central bank chooses $q$ such that it can prevent the real liquidation of $L^{*}$ assets at the lowest price impact, i.e. $\underline{q}=p_{1} \rho$. At this price, the individual costs of liquidating the asset $\left(R-p_{1} \rho\right)$ and the costs of selling it to the central bank in exchange for cash $(R-\underline{q})$ are identical. (9c), (9d) and (16) show that individual investors are indifferent between liquidating, selling to the central bank and selling on the market as $\underline{q}=p_{1} \rho=q$. Nevertheless, the central bank intervention raises the welfare of investors ceteris paribus because it lessens the cash-in-advance constraint via the endogenous rise of $p_{1}$ and the 
corresponding increase in the value of the asset in $t=1, p_{1} \rho=q=q \cdot{ }^{35}$ Since the nominal income of workers and the supply of goods $Y_{1}^{s}=\bar{Y}$ are fixed, the price increase causes a redistribution from workers to investors in $t=1$.

The anticipation of central bank intervention also affects the initial investment decision of investors. The first-order condition for optimal investment in the asset is $(9 \mathrm{~g})$,

$$
\frac{d L}{d s}=\int_{-\infty}^{\infty}[\lambda(R-1)-\mu] f(\gamma) d \gamma=0 .
$$

In the optimum, the excess return of the asset over money $(R-1)$ evaluated with the expected marginal utility of wealth $\lambda$ equals the expected marginal utility of money's liquidity services $\mu$. Investors anticipate that the central bank will provide extra liquidity for some realisations of $\gamma$. These interventions raise the rationally expected price of goods $E_{0}\left[p_{1}\right]$ relative to the one without expectations of interventions. The higher expected price level lowers the value of money's nominal payoff relative to the liquidated asset's real payoff of $\rho$ in $t=1$, or, in nominal terms, raises the nominal value of a liquidated asset $p_{1} \rho$ relative to the constant nominal payoff of money of 1 . Since the asset becomes more valuable relative to money, investors will increase their investment $s$. This represents the so-called moral hazard effect of central bank intervention because investors increase their holdings of the asset whose value is possibly subject to liquidity risk as they anticipate the liquidity provision by the central bank.

Proposition 3 The anticipation of a central bank intervention in $t=1$ to limit the extent of real liquidations of the asset causes an increase in the investment in the asset $S$ relative to the case without the possibility of a central bank intervention.

Proof. The moral hazard effect arises for two reasons. Taking the aggregate investment level $S$ as given, the higher goods price $p_{1}$ first raises the optimal amount of assets liquidated or sold to the central bank because $\left.\frac{\partial z}{\partial p_{1}}\right|_{\gamma>L I Q}>0$ (for $z, \lambda, \mu$, see the last column of table 2). This is reflected in (22) in a lower expected marginal utility of money, $\left.\frac{\partial \mu}{\partial p_{1}}\right|_{\gamma>L I Q}<0$, and a greater marginal utility of wealth, $\left.\frac{\partial \lambda}{\partial p_{1}}\right|_{\gamma>L I Q}>0$. Second, the increase in $p_{1}$ lowers the threshold of the realisation of $\gamma, L I Q=\frac{\beta(W-S)}{p_{1} \rho S}$, for which $Z$ and $L$ become positive. Since $C I A=\frac{\beta(W-S)}{R S}$ remains unchanged for a given $S$, the lower $L I Q$ reduces the intermediate range $C I A \leq \gamma \leq L I Q$ for which the effect of the liquidity shock is fully absorbed by the asset price and consumption remains unchanged (see table 2). The constant consumption levels imply that the marginal utility of wealth, $\lambda$, is also constant in this range, while the cash-in-advance constraint becomes very costly, i.e. $\mu$ rises rapidly with $\gamma$. Equation (22) shows that a

\footnotetext{
${ }^{35}$ See also figure 6 and the discussion of the moral hazard effect below.
} 


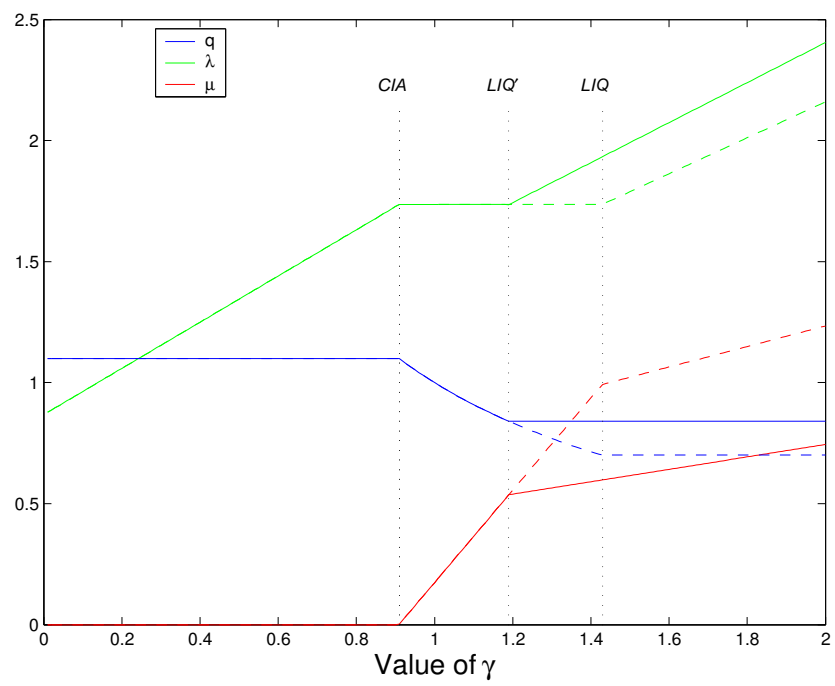

Figure 6: $q, \lambda, \mu$ as a function of $\gamma$ and different parameter values for $p_{1}=1$ (dashed line) and $p_{1}=1.2$ (solid line).

greater expected marginal utility of wealth and a smaller expected marginal utility of money increase the optimal individual investment $s$. This raises also the aggregate investment $S=\int_{i \in I} s d i$ in equilibrium.

The two effects can be seen in figure 6 which replicates figure 4 for the case of no central bank intervention. It shows the shift to the left of the threshold $L I Q$, i.e. the right kink in the three curves, and the higher values of $\lambda$ and the lower values of $\mu$ in the range of $\gamma>L I Q$ for a greater price $p_{1}$ due to a central bank intervention.

The moral hazard effect of Proposition 3 can be so severe that investors stop holding money as stated in the following Corollary 2:

Corollary 2 Holding no money from $t=0$ to $t=1$ represents an equilibrium if investors expect the central bank to intervene at a price q greater than 1 .

Proof. Assume all investors except $i$ hold only the asset, i.e. $S=W$. Then, $C I A=L I Q=0$ and the central bank has to intervene with certainty. Equation (22) simplifies to $\frac{d L}{d s}=\int_{-\infty}^{\infty}\left[\frac{(\beta+\gamma)(\underline{q}-1)}{w-s+\underline{q} s}\right] f(y) d \gamma \geq 0$ which will be strictly positive for $E_{0}[\underline{q}]>1$ as $\gamma$ has a positive support, $\operatorname{cov}(\gamma, \underline{q})>0$ and the denominator $w+(\underline{q}-1) s>0$. Hence, investing the full endowment $w$ in the asset will be optimal for $i$, i.e. $s=w$, and $S=W$ represents an equilibrium.

Corollary 2 implies that the parameters of the model, for example the real payoff of liquidation $\rho$ or the weight on output stabilisation $\omega$, have to be chosen such that the liquidity provision is sufficiently costly and $E_{0}[\underline{q}]$ sufficiently 
smaller than 1 in order to prevent the possibility of a complete moral hazard scenario caused by full insurance against liquidity shocks provided by the central bank.

What happens to the welfare of workers? Given the investment $S$, their welfare clearly rises if the central bank's relative weight on output in the loss function (13), $\omega$, represents their own preferences. The central bank sets $L^{*}$ and the corresponding price $\underline{q}$ such that the marginal cost of the price increase equals the marginal benefit of less liquidated assets in equation (20). The increase in $S$ due to the moral hazard effect is double-edged, however: The higher real investment causes a rise in producible output $\bar{Y}$ as $\partial \bar{Y} / \partial K \cdot d K / d S>0$. At the same time, it increases the extent of desired liquidations $Z^{*}$ and central bank intervention $L^{*}$ ceteris paribus. In general, the overall welfare effect for workers depends on the gain from greater output $\bar{Y}$ due to the increase in $S$ relative to the associated costs in $t=1,2$. The following section discusses the optimal monetary policy when the central bank takes this additional trade-off into account. That section also examines what happens if not only investors, but also workers anticipate the central bank intervention.

\subsection{Monetary policy under commitment and other model ex- tensions}

In section 3.4, the optimal central bank intervention in $t=1$ was calculated based on the central bank loss function (13) after the realisation of the liquidity shock and given aggregate investment $S$. This reflects the absence of a commitment possibility of the central bank in this model. In other words, the solutions presented so far represent optimal monetary policy under discretion. The optimal second-best solution given the cash-in-advance constraint, however, could be achieved by a central bank with the possibility to commit to a specific intervention policy in $t=1$ at $t=0$.

In that case, the central bank has to optimally weight the increased aggregate supply $\bar{Y}$ associated with the moral hazard-effect against the costs of liquidations and interventions in $t=1$ and 2. More generally, if private investors anticipate a liquidity insurance by the central bank, they hold less liquidity and invest their funds more productively. A lower level of aggregate liquidity, however, makes the financial sector less resilient, such that financial crises and central bank interventions become more likely.

Hence, the loss function (13) has to be extended to take the productivity gain from the moral hazard effect into account. As before, the loss increases in $p_{1}-p_{1}^{*}$ and the output costs of liquidations $\Delta(Z)$. Additionally, the loss decreases with

aggregate output $\bar{Y}$, such that optimal monetary policy under commitment 
solves

$$
\min _{S, L} E_{0}\left[\mathcal{L}\left(\bar{Y}, p_{1}-p_{1}^{*}, \Delta(Z)\right)\right]
$$

to find the optimal level of private investments $S$ and the optimal liquidity provision $L$ conditional on the realised liquidity shock.

So far in this paper, workers build their price expectations based on the money holdings $W-S$ of investors (see sections 2.2.2 and 2.3.2). The question what happens if not only investors, but also workers anticipate the central bank intervention, is related to the brief discussion in footnote 25 of the effects if workers' formed their price expectations in the wage negotiations with rational expectations rather than the quantity equation. For a given level of $S$, the central bank will provide extra liquidity if $\gamma>L I Q$. This increases the expected amount of cash available for purchases of consumption goods relative to the situation without central bank intervention and thus raises the expected price of consumption goods or - in a repeated version of the model - the expected inflation rate. Since rational workers want to be compensated for the higher expected price with higher nominal wages, this leads to an 'inflation bias' which the central bank should consider in the optimal monetary policy under commitment. ${ }^{36}$ But once wages are determined, the central bank can always provide more liquidity than expected. Hence, the trade-off in $t=1$ between redistribution losses for workers today versus less supply tomorrow continues to exist, independent of the way workers form their price expectations.

Another important feature of the central bank intervention is the possibility of a sterilisation of its intervention before the additional money causes price increases on the goods market. The example of September 11 in section 1.2 shows that the Fed was indeed able to quickly sterilise the emergency liquidity issued directly after the terrorist attacks. But this liquidity crisis was mostly limited to the payments and settlement system. In the other two examples of section 1.2, the crises in 1987 and 1998, the Fed had to lower interest rates despite buoyant GDP growth and rising inflation and provide liquidity for a much longer time to calm the markets (see figure 1 and the discussion in section 1.2). In these cases, the trade-off analysed in this paper increases in relevance for the optimal policy response to the crises. ${ }^{37}$ Nevertheless, a sterilisation-

\footnotetext{
${ }^{36}$ Note that although the moral hazard effect lowers private money holdings $W-S$, the central bank intervention still raises the expected overall nominal demand from investors on the goods market. The reason is that investors reduce their money holdings precisely because they expect an easing of their CIA on average relative to the situation without central bank intervention.

${ }^{37}$ Taylor (2005) supports the liquidity provision principle and thus a temporary departure of interest rates from the recommendations of a Taylor rule that includes only inflation and output. But he argues that policy should have returned to a standard rule more quickly after the crises in 1987 and 1998, i.e. sterilised the liquidity provision (Taylor, 2005, p. 114).
} 
possibility of interventions could be easily included into the model by making the nominal aggregate demand shock $\eta$ that spills over from the asset to the goods market a function of the sterilisation possibilities of the central bank.

In the model so far, the individual costs of emergency liquidity provision $(R-\underline{q}) l$ represented a deadweight loss. Actually, these costs for investors correspond to seigniorage income for the central bank. If the central bank or the government used this seigniorage to buy consumption goods in $t=2$, the aggregate demand equation (12) included the additional term $(R-\underline{q}) L$ in the numerator. The welfare effects depend on the use of the real seigniorage income and should be taken into account accordingly when the central bank provides liquidity in $t=1$. The inclusion of seignorage does not change the general trade-offs in the model, but it reduces the costs of liquidity provision if the seigniorage income is distributed to workers.

Finally, the traditional Bagehot (1873) principles suggest that the central bank should provide liquidity only to an illiquid, but solvent bank. The judgement between illiquidity and insolvency requires a lot of information about banks' assets and liabilities on behalf of the lender of last resort, the central bank. This identification problem transfers to financial markets, where the central bank faces the question if asset price declines are caused by illiquidity or by deteriorating fundamentals. In contrast to the case of financial intermediaries, this judgement seems to be less difficult on financial markets since a number of illiquidity measures exist and are easily observable: For example, bid-ask spreads, the quoted depth, i.e. the number of shares available at the bid/ask price, respectively, the volatility of returns and the size of order flows (see, e.g., Chordia et al., 2005). If all of these criteria signal liquidity problems, the central bank clearly faces a liquidity crisis. It should then act as a 'liquidity provider of last resort' and judge its actions according to the framework developed in this paper. $^{38}$

\section{Idiosyncratic risk}

Having analysed the asset market, the goods market and central bank interventions under aggregate risk in the previous sections, I now focus on the question under which circumstances idiosyncratic shocks can influence asset prices. If liquidations are optimal for individual investors, the optimal central bank intervention and the spillover effects to the goods market are identical to the case under aggregate risk. Hence, this section concentrates on the asset market.

\footnotetext{
${ }^{38}$ Besides, my model could also easily capture worsening fundamentals by a lower real value of the liquidation technology, $\rho$.
} 


\subsection{Standard model}

The optimal investment decision problem for an individual investor under idiosyncratic risk resembles the one under aggregate risk with central bank intervention in $(14)^{39}$

$$
\begin{aligned}
\max _{s, c_{1}, c_{2}, \hat{s}, z, l} E\left[U\left(c_{1}^{\prime}, c_{2}\right)\right] & =\int_{-\infty}^{\infty}\left(\zeta_{i} \ln \left(c_{1}+\rho z\right)+\beta \ln c_{2}\right) f(\gamma) d \gamma \quad \text { s.t. } \\
p_{1} c_{1}+p_{2} c_{2} & \leq w-s+R s+(R-q) \hat{s}-R z-(R-\underline{q}) l \\
p_{1} c_{1}+q \hat{s} & \leq w-s+\underline{q l} \\
0 & \leq z \leq s ; 0 \leq l \leq s ; l+z \leq s
\end{aligned}
$$

and is solved analogically. The first-order conditions are the same as in section 3.2 with $\zeta_{i}$ replacing $\gamma \cdot{ }^{40}$ Again, market clearing in $t=1$ requires that $\hat{S}=$ $\int_{i \in I} \hat{s} d i=0$. Hence, the asset price $q$ has to adjust to equalise excess demand and supply of assets by individual investors. The crucial difference to the case with only aggregate risk is that the market clearing condition does not imply that $\hat{s}=0$ and no assets are traded.

The demand for shares in $t=1$ by investor $i, \hat{s}_{i}$, is determined by

$$
\hat{s}_{i}=\frac{\beta(w-s)-q \zeta_{i} s}{q\left(\beta+\zeta_{i}\right)} .
$$

Note that that the Cobb-Douglas utility function (2) implies that $\hat{s}_{i}$ is a convex function of $\zeta_{i}$ for a given asset price $q$ as $\partial^{2} \hat{s}_{i} /\left(\partial \zeta_{i}\right)^{2}>0 .{ }^{41}$

Assume that each investor has an ex-ante probability of one half of belonging to group $A$ who receive a shock $\zeta_{A}$ and to group $B$ with shock $\zeta_{B}$, respectively, and $\zeta_{A} \geq \zeta_{B}$ without loss of generality. The condition $E\left[\zeta_{i}\right]=1$ and the positive support of $\zeta_{i}$ imply $\zeta_{A} \in[1 ; 2),\left(\zeta_{A}+\zeta_{B}\right) / 2=1$ and the absence of an aggregate shock. As usual, market clearing requires

$$
\int_{i \in A} \frac{\beta(w-s)-q \zeta_{A} s}{q\left(\beta+\zeta_{A}\right)} d i+\int_{i \in B} \frac{\beta(w-s)-q \zeta_{B} s}{q\left(\beta+\zeta_{B}\right)} d i=0 .
$$

The pricing kernel for $q$ becomes

$$
q=\min \left[\frac{\beta(1+\beta)(W-S)}{\left[\zeta_{A}\left(2-\zeta_{A}\right)+\beta\right] S} ; R\right] \quad \text { for } \quad \frac{\beta(W-S)}{S} \geq p_{1} \rho
$$

with $W$ and $S$ defined as before. Without idiosyncratic shocks, i.e. $\zeta_{i}=1$,

\footnotetext{
${ }^{39}$ In order to explicitly exclude short sales, the constraint $\hat{s} \geq-s$ had to be added to (24). Footnote 41 shows that this is redundant given the specification of the model.

${ }^{40}$ That means equations (9a) to (9d), (9g), (15a), (15b) and (16).

${ }^{41}$ Furthermore, $\hat{s}_{i}>-s$ as $\beta(w-s)>-q \beta s$ such that the short sale constraint is redundant.
} 

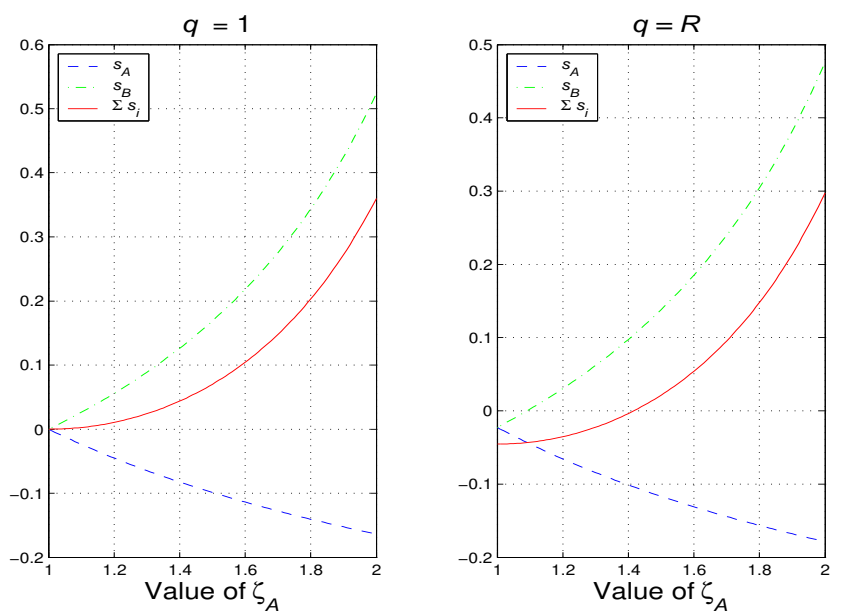

Figure 7: Convexity of $\hat{s}_{i}: \hat{s}_{A}, \hat{s}_{B}$ and $\sum \hat{s}_{i}=\hat{s}_{A}+\hat{s}_{B}$ as a function of $\zeta_{A}$ for $q=1$ and $q=2$.

equation (26) simplifies to $q=\beta(W-S) / S$, the same asset price as for $\gamma=1$ in section 2.3.1. The condition $\beta(W-S) / S \geq p_{1} \rho$ excludes liquidations $z>0$ for $\zeta_{i}=1 .{ }^{42}$

Note that $q$ in (26) increases in the heterogeneity of $A$ and $B$, i.e. in the absolute value $\left|\zeta_{i}-1\right|$. The reason is the convexity of $\hat{s}_{i}$ in (25) mentioned above. The convexity implies that the additional demand of the agents with the low liquidity shock $\zeta_{B}$ is always sufficiently large such that agents with the high shock $\zeta_{A}$ do not need to liquidate their asset. Figure 7 illustrates the convexity of $\hat{s}_{i}$ for $R=1 / \beta=1.1$ and $S=\beta /(1+\beta) W$, the investment in the case of certainty. The solid line represents the excess demand for the asset which is 0 for $\zeta_{A}=1$, given an asset price of $q=1$ in the left panel. For $\zeta_{A}>1$ (and thus $\left.\zeta_{B}=2-\zeta_{A}<1\right), \hat{s}_{B}$ rises faster than $\hat{s}_{A}$ falls, the excess demand becomes positive and $q>1$ for $\zeta_{A}>1$. For $\zeta_{A} \approx 1.413$, the asset price increases to $q=R$, since the excess demand is 0 at this combination of $q$ and $\zeta_{A}$ in the right panel. For $\zeta_{A}>1.413$, investors hit by the low shock $\zeta_{B}$ transfer money into $t=2$ as their CIA becomes unbinding.

To summarise the effects, the structure of the model, in particular the CobbDouglas utility function (2) that causes the convexity of $\hat{s}_{i}$ and the dissolution of risk in $t=1$, imply that idiosyncratic shocks alleviate the CIA given a fixed initial investment $S$. In general, however, idiosyncratic shocks can have a negative impact on asset prices if the absorption capacity of the market is limited. This happens in reality and in other models for example if investors are risk-

${ }^{42}$ The more general form of $(26)$ is $q=\min \left[\max \left(\frac{\beta(1+\beta)(W-S)}{\left[\zeta_{A}\left(2-\zeta_{A}\right)+\beta\right] S} ; p_{1} \rho\right) ; R\right]$. 
averse and future returns are risky (see, e.g., Huang and Wang, 2006).A further feature of reality is the presence of brokers and market-makers on financial markets rather than a Walrasian auctioneer. As they smooth price fluctuations by providing liquidity to financial markets, they earn income in the form of bid-ask spreads. Models that analyse the microstructure of financial markets explain the behaviour of these market participants and the implications for transaction prices. The following section presents an extension to the standard model of this section that includes transaction costs in the form of bid-ask spreads, and section 4.3 discusses different mechanisms how small shocks can have large impacts.

\subsection{Model with transaction costs}

The market microstructure literature has developed models based on orderhandling costs, asymmetric information or strategic behaviour, where idiosyncratic shocks can have (severe) impacts on asset prices. As Biais, Glosten and Spatt (2005, p. 218) formulate it:

In perfect markets, Walrasian equilibrium prices reflect the competitive demand curves of all potential investors. While the determination of these fundamental equilibrium valuations is the focus of (most) asset pricing, market microstructure studies how, in the short term, transaction prices converge to (or deviate from) long-term equilibrium values.

A full market microstructure model is beyond the scope of this paper, but the most important literature in this field is discussed in section 5.3. A simple way to summarise the relevant issues of market microstructure as developed, e.g., in O'Hara (1995) and Biais et al. (2005), is to assume transaction costs in the form of a bid-ask spread $\Xi$ that decreases in total liquidity $M=\int_{i \in I} m d i$ available and increases in the order size $\hat{s}_{i}$, i.e. $\Xi=\Xi\left(\begin{array}{c}M, \hat{s}_{i} \\ -+_{+}\end{array}\right) \cdot{ }^{43}$ Market-makers buy the asset in $t=1$ at a bid price of $q^{\text {bid }}$ from investors with the high shock $\zeta_{A}>1$ and sell it to the low-shock types $B$ with $\zeta_{B}=2-\zeta_{A}$ at an ask price $q^{\text {ask }}=q^{\text {bid }}+\Xi$. They earn the spread $\Xi$, with which they buy consumption goods on the goods market in $t=1$ such that aggregate demand for goods is not directly affected by the presence of market-makers in the model.

\footnotetext{
${ }^{43}$ For the positive relation between order size and bid-ask spreads, see chapters 3 and 6 in O'Hara (1995), for example. $M$ represents a proxy for the size of the market making sector, which has a negative impact on the size of the spread as demonstrated in different models in O'Hara (1995). It also captures the public good character of liquidity as discussed below. Amihud and Mendelson (1986) provide empirical evidence for the role of bid-ask spreads in asset pricing.
} 
The transaction cost $\Xi$ is a measure of an asset's liquidity from the microperspective $^{44}$ and has a number of interpretations beyond completely exogenous transaction costs as, e.g., in Vayanos (2004) and Favero, Pagano and von Thadden (2006): It represents the time-varying illiquidity cost of shares in Acharya and Pedersen (2005) as $\hat{s}$ varies with the size of the shock. ${ }^{45}$ It also captures search costs from search and matching models of financial markets as developed by, e.g., Duffie, Gârleanu and Pedersen (2005) because more available liquidity increases the probability of quickly finding a buyer, but larger orders decrease it. A further interpretation of $\Xi$ are the random order-execution delays in Weill (2007). They are low in normal times but can become severe in times of liquidity crises such as October 1987 or September 1998 as described in section 1.2. These are precisely the times when order sizes tend to be large and aggregate liquidity tends to be low, at least until a central bank intervention calms markets.

Adding the transaction cost $\Xi$ to the standard model (24) for idiosyncratic risk results in

$$
\begin{aligned}
& \max _{s, c_{1}, c_{2}, \hat{s}, z} E\left[U\left(c_{1}^{\prime}, c_{2}\right)\right]=\int_{-\infty}^{\infty}\left(\zeta_{i} \ln \left(c_{1}+\rho z\right)+\beta \ln c_{2}\right) f(\gamma) d \gamma \quad \text { s.t. } \\
& p_{1} c_{1}+p_{2} c_{2} \leq w-s+R s+\left(R-q^{j}\right) \hat{s}-R z-(R-\underline{q}) l \\
& p_{1} c_{1}+q^{j} \hat{s} \leq w-s+\underline{q} l \\
& 0 \leq z \leq s ; 0 \leq l \leq s ; l+z \leq s \\
& q^{j}= \begin{cases}q^{\text {bid }} & \text { for } \quad \zeta_{i}=\zeta_{A} \\
q^{\text {ask }}=q^{\text {bid }}+\Xi(M, \hat{s}) & \text { for } \quad \zeta_{i}=\zeta_{B} .\end{cases}
\end{aligned}
$$

In the equilibrium with $\zeta_{A}>\zeta_{B}$, investors of group $A$ cannot be buyers of $s$, i.e. $\hat{s}_{A} \leq 0$, such that their constraints are based on $q^{\text {bid }}$, while investors of group $B$ cannot be sellers of $s$, i.e. $\hat{s}_{A} \geq 0$, and their constraints include $q^{\text {ask }}$.

The spread drives an additional wedge between the assets final payoff $R$ and the achievable price for sellers, $q^{\text {bid }}$. Hence, costly liquidation $(z>0)$ is optimal for a wider range of parameters and shocks, which in turn leads to an extension of central bank intervention as the central bank optimally weights the output costs of intervention against the price increase associated with additional money.

Finally, the negative dependence of $\Xi$ on aggregate liquidity $M=W-S$ introduces the public good character of liquidity and financial stability into the

\footnotetext{
${ }^{44}$ Other measures of liquidity such as the size of order flows were listed in section 3.6.

${ }^{45}$ Furthermore, $M$ may be time-varying in a dynamic model in which this three-period game is played repeatedly.
} 
model. ${ }^{46}$ While a decrease in $S$ would lower the expected bid-ask spread and thus decrease the probability of costly liquidation in $t=1$, the individual investor does not take this external effect into account in $t=0$ since she is a price taker, i.e. $d M / d s=0$.

\subsection{From small shocks to large impacts: Propagation mecha- nisms}

It may be questionable if transaction costs $\Xi$ can become so large that idiosyncratic shocks can cause financial crises. But modern financial systems exhibit a number of feedback mechanisms that can amplify small shocks once the price impact exceeds a certain threshold. ${ }^{47}$ These propagation mechanisms include margin calls, capital adequacy ratios, marking to market accounting rules and modern risk management.

Margins serve as collateral on markets for derivatives and for credit-financed investments. Combined with some form of a financing constraint, they can generate negative feedback mechanisms. In Morris and Shin (2004), 'liquidity black holes' arise because of exogenous loss limits for traders. Extending the market microstructure model of Grossman and Miller (1988), Brunnermeier and Pedersen (2007) use the concepts of market liquidity and funding liquidity: In normal times, capital constrained traders use external funds to smooth price fluctuations and provide market liquidity. If traders' outside financiers cannot distinguish illiquidity shocks from fundamental one ${ }^{48}$ and increase the required margins in response to an increase in price volatility, they can create a vicious circle: A negative liquidity shock causes losses and higher margins for traders, which reduces their ability to provide market liquidity and thus further increases traders' losses and required margins. Schnabel and Shin (2004) use the financial crisis in northern Europe in 1763 as a historic example of such negative feedback effects. Sauer (2002) adopts their model to explain the LTCM-crisis in 1998.

Closely related to margin calls for leveraged investors are capital adequacy ratios for banks. Shin $(2005 b, a)$ and Illing (2007) show that capital adequacy requirements for banks can set off a vicious circle of asset sales similar to the one triggered by the funding constraints in Brunnermeier and Pedersen (2007). ${ }^{49}$

\footnotetext{
${ }^{46}$ Other papers that model liquidity as a public good include Holmström and Tirole (1998), Huang and Wang (2006) and Illing (2007). For a practitioner's view, see Geithner (2006).

${ }^{47}$ In the model of this paper, this may be particularly relevant if idiosyncratic shocks are combined with positive aggregate shocks.

${ }^{48}$ Brunnermeier and Pedersen (2007) borrow this idea from the performance-based arbitrage argument in Shleifer and Vishny (1997), which is also applied for example in Gromb and Vayanos (2002).

${ }^{49}$ In Shin (2005b), financial intermediaries want to maintain a minimum level of leverage. This
} 
Recent international reform proposals of accounting rules suggest to extend the use of market prices in accounting of financial firms instead of valuations based on historical costs. While such marking to market gives a clearer picture of the true value of firms in general, it may cause excessive price volatility, i.e. volatility not reflecting fundamentals, and exacerbate or even trigger a financial crisis. In the model by Shin (2005b,a), marking to market is not necessary (Illing, 2007, p. 10), but accelerates the feedback effects via banks' balance sheets. Plantin, Sapra and Shin (2005) describe in a global games setup, how marking to market accounting rules can cause large losses in less liquid markets because asset sales are strategic complements under this accounting regime. They find that the damage done by marking to market is greatest when claims are long-lived, illiquid and senior. Cifuentes, Ferrucci and Shin (2007) combine marking to market accounting with regulatory solvency requirements to show that balance sheet interlinkages among financial institutions and contagion via changes in asset prices can cause contagious failures of financial institutions as a result of small shocks.

Financial risk management is a core competence of modern financial institutions and continuously evolving, not least in response to financial crises. In the 1980's, portfolio insurance became a popular form of risk management for investment funds. The discussion of the 1987-crash in section 1.2 highlights the negative impact of portfolio insurance during the crash. Today, value at risk ( $\mathrm{VaR})$ has become the standard risk measure used by financial institutions. Banks' capital requirements in the Basel-I accords have been linked to market risk based on VaR-calculations since 1998. Yet, VaR is no panacea, either. For example, Gârleanu and Pedersen (2007) show that a feedback effect can arise between tighter risk management and a reduction in liquidity. The former reduces the amount of liquidity provided to the market and the latter increases the effective risk of positions because it takes longer to sell them. The heart of the problem is the endogeneity of risk as described by Danielsson (2001) and Danielsson and Shin (2003). Financial market risk is not given exogenously by nature, but depends on the actions of market participants. This property becomes particularly important if financial institutions follow very similar investment strategies ${ }^{50}$ and use the same standardised methods for their risk management (IMF, 1998).

Stress testing or liquidity-adjusted VaR measures are ways to incorporate liq-

creates a 'virtuous circle' of rising asset prices and increased lending. Thus, 'booms can be understood as a mirror image of liquidity drains.' While Shin (2005a) just mentions possible asymmetries due to default or inefficient liquidations, Illing (2007) extends Shin's model with a kinked net supply curve of assets, in this case property, due to information asymmetries. These market imperfections cause asymmetries between boom and bust periods in asset prices.

${ }^{50}$ Many proprietary traders of investment banks copied the until then highly profitable strategies of LTCM in 1998 (see, e.g., Morris and Shin, 1999, p. 52). 
uidity risk into risk management. Nevertheless, the fundamental problem of financial risk's endogeneity remains unsolved.$^{51}$ In particular, individuals neglect the external effect of their decisions on aggregate liquidity. The public good character of liquidity, however, becomes most relevant during financial crises.

\section{Related theoretical literature}

Besides the different propagation mechanisms discussed in the previous section, the model developed in this paper is linked to a number of theoretical contributions in the literature. This section reviews papers that analyse the Greenspan put option, segmented asset and goods markets as well as market microstructure theory and papers on the public supply of liquidity.

\subsection{Greenspan put option}

The 'Greenspan Put', i.e. the supposed insurance against severe financial turmoil by the Federal Reserve under Alan Greenspan, has become a well-known argument in the popular financial press. To my knowledge, only Miller, Weller and Zhang (2002) and Illing (2004) have developed an explicit theoretical analysis of the Greenspan put, focusing on the situation in which the central bank insures against asset price declines caused by a deterioration of the fundamental value of the asset.

In Miller et al. (2002), the expected present value of all current and future dividends determines the fundamental value of shares. Better management of financial crises by the Fed under Alan Greenspan, as indicated by the examples of 1987 and 1998 in section 1.2, may have fundamentally reduced the risk of shares and thus increased their fundamental value. But Miller et al. (2002) argue that investors additionally hold the erroneous belief that the Fed could insure them against any fall in asset prices, i.e. not only against price drops that are due to a financial crisis but also against 'normal' declines that are due to a decrease in current and future dividends. For example, lower productivity growth than expected may reduce dividends and thus justify and require a revaluation of shares. Hence, investors appear to have overconfidence in the ability of the Fed to put a lower bound, a put option, on the share price and this leads to an overvaluation of shares which represents a bubble. The bubble is, however, completely independent of actual monetary policy, which is the focus of the present paper.

\footnotetext{
${ }^{51}$ In Gârleanu and Pedersen (2007), the feedback effects are even stronger for a liquidity-adjusted VaR than a standard one.
} 
Illing (2004) uses a model that concentrates on nominal debt and financial intermediation. Equity owners have a residual claim on the risky payoff of firms that are leveraged with nominal bank debt. A severely negative aggregate shock to the fundamental value of firms limits their ability to repay their debt, which in turn leads to the threat of bank runs by depositors. The collapse of banks would extinguish the knowledge capital from relationship lending in the economy and prompts the central bank to provide liquidity to the banks. The additional money reduces the real value of firms' nominal debt, which represents a capital gain for equity owners. The anticipation of the monetary injection causes a bubble ex ante, as it raises the firms' share price above its fundamental value. Illing (2004) notes that the central bank in his model faces a trade-off between the bubble created by moral hazard, i.e. the expected capital gain, and the risk associated with the disruption of financial intermediation.

The model by Illing (2004) can be easily classified in terms of the framework provided in this paper, although I focus on financial markets rather than intermediation and leverage is not crucial in my model. After the realisation of the aggregate shock, the central bank in Illing's model does not face any tradeoff because ex post it is always optimal to prevent bank runs and keep banks' knowledge capital. ${ }^{52}$ This is different in my model where the central bank optimally chooses between inflation today and an output loss tomorrow after the shock. The trade-off emphasised by Illing only arises if the central bank has the possibility to commit to a specific intervention policy in response to a negative shock. This situation is akin to the optimal commitment solution discussed in section 3.6 in my model.

Both Miller et al. (2002) and Illing (2004) analyse the central bank insurance against asset price declines caused by a deterioration of the fundamental value of the asset, either erroneously expected or actually conducted. This represents probably a part of the public perception of the alleged 'Greenspan put'. But the analysis in my model is more closely related to a 'liquidity provision principle', i.e. a temporary deviation of central bank policy from a standard Taylor rule that responds only to output and inflation in order to inject large quantities of liquidity in a financial crisis (Taylor, 2005). It is the dramatic increase in $\mu$, the marginal utility of cash's liquidity services, that induces investors to partly liquidate their assets and triggers the central bank's response, not a change in the fundamental pay-off of the asset $R$. Hence, it is the microeconomic view of liquidity, the missing ability to sell assets quickly and costlessly, that causes a monetary injection in my model.

\footnotetext{
${ }^{52} \mathrm{~A}$ similar effect occurs in Illing (2007) within a different model with propagation effects as discussed in section 4.3. There, the central bank always lowers interest rates to prevent fire sales of assets by distressed banks which have to restore their capital adequacy requirements.
} 


\subsection{Market segmentation}

A crucial assumption in the model relates to the limited participation on the asset market, as workers cannot buy assets. If they could do so and their liquidity needs were not perfectly correlated with investors liquidity shocks, they might provide the extra liquidity needed to smooth investors liquidity shocks. The assumption of segmented markets follows the models in Allen and Gale (1994, 2005) and Huang and Wang (2006), where limited market participation emerges from participation costs. ${ }^{53}$ The same impact has the assumption of separate cash-in-advance constraints on the asset and the goods market for all agents in Gale (2005). Gale (2005) uses his model to show that liquidity must be costly in order to guarantee the determinacy of the price level. Furthermore, the asset price fluctuates without affecting the goods price as the central bank stabilises the goods prices via its real seigniorage income. Both features are present in my model as the cash-in-advance constraint never binds $(\mu=0)$ if the central bank provides liquidity for free, i.e. $\underline{q}=R$. Asset price volatility without spillover effects to the goods market occurs in my model in the intermediate range of $C I A<\gamma<L I Q$. The main contribution of my paper is the analysis of financial crises and the focus on emergency liquidity provision rather than on seigniorage income as in Gale (2005).

In reality, participation in markets is limited because economic agents lack the required expertise, have limited attention, institutional barriers or other costs of entry (Gale, 2005). Empirically, Landon-Lane and Occhino (2006) use Bayesian techniques to estimate the fraction of households participating in financial markets to be approximately 22\%, while Campbell and Mankiw (1989) find that about $40 \%$ to $50 \%$ of the population in the U.S. consume only their current income rather than smooth their consumption via savings and dissavings. Statistics from the Survey of Consumer Finances 2004 reported in Bucks, Kennickell and Moore (2006) show that merely $20.7 \%$ of U.S. households hold publicly traded stocks directly and only $48.6 \%$ hold them directly or indirectly, e.g. via retirement accounts.

\subsection{Market microstructure theory}

The literature on market microstructure analyses the trading mechanism for financial securities and its impact on short-term asset price behaviour. O'Hara (1995) provides an excellent summary of the earlier literature, Biais et al. (2005) survey more recent developments. Amihud, Mendelson and Pedersen (2005)

\footnotetext{
${ }^{53}$ In Allen and Gale (1994), private agents decide about their participation on the asset market before liquidity shocks occur, in Huang and Wang (2006) after the realisation of idiosyncratic shocks which can thus have aggregate effects. Other papers that use models with limited market participation include Alvarez, Atkeson and Kehoe (2002) and Williamson (1994), for example.
} 
review the connection between liquidity as derived from the theoretical and empirical microstructure literature and asset pricing.

A common feature of this literature is that it does not distinguish between nominal and real assets and payoffs. Technically, most models maximise agents' expected utility of terminal wealth (see the models in O'Hara, 1995). For example, Grossman and Miller (1988) model liquidity as the price of immediacy. Market makers are willing to smooth temporary order imbalances for an asset with a risky final payoff if they can expect a positive excess return compared to the investment in a riskless asset.

An alternative way to model asset trading and possible illiquidity is the search and matching literature that has been inspired by Duffie et al. (2005). Again, these models do not differentiate between nominal and real payoffs as an asset pays one unit of a consumption good per period that serves as numéraire. One application of the model by Duffie et al. (2005) are endogenous feedback effects between risk-management and liquidity in Gârleanu and Pedersen (2007) as discussed in section 4.3.

By providing a framework that links asset price developments caused by liquidity shocks to the real sector of the economy via two spillover effects, this paper makes one of the first steps to link the findings from the market microstructure literature with the analysis of optimal monetary policy in the macroeconomic literature.

\subsection{Public supply of liquidity}

A prominent paper that investigates public provision of liquidity is Holmström and Tirole (1998), but it differs from the model in this paper in important respects. First, liquidity is defined as the availability of instruments to transfer wealth across periods rather than to sell assets quickly and costlessly. Furthermore, the paper looks at the production side of the economy as firms may have a demand for liquidity to refinance their investment projects. Firms financing is subject to an agency problem such that firms cannot pledge the full value of the firm as collateral for credit lines or marketable assets. While this is not problematic without aggregate uncertainty given the right private institutions such as banks, private 'liquidity' is insufficient in the presence of aggregate uncertainty. The government can overcome the agency problem and issue government bonds that are not subject to the agency problem because it can enforce tax payments. The social optimum in the model can be achieved with state-contingent government bonds, i.e. an active management of public liquidity, as their existence averts any private excess liquidity. Hence, Holmström and Tirole (1998) is not a paper about financial crises but rather about 
the involvement of the state in the financial system in normal times.

More generally, however, public provision of liquidity refers to the lender of last resort activity of a public authority, usually the central bank, as emergency liquidity assistance to the financial system. Most of the literature on the lender of last resort concentrates on banks and the interbank market. The collection of a wide range of papers on the lender of last resort in Goodhart and Illing (2002) includes only one paper by Kaufman (2002) that discusses the response to fire sales on asset markets in an informal way. More recent treatments like Freixas, Parigi and Rochet (2004) also neglect liquidity crises on asset markets, which are the focus of my paper. ${ }^{54}$ Given the substantial growth of financial markets relative to traditional banking in continental Europe and the continuous introduction of new financial instruments like credit derivatives, an appreciation of the effects of liquidity provision in response to liquidity crises on financial markets appears to be necessary.

\section{Conclusion}

The different specifications of the general model in this paper help to provide guidance for central banks in the event of liquidity crises. Confronted with a liquidity crisis, the central bank faces a trade-off between injecting liquidity and thus incurring risks to price stability and negative supply effects in the future. The size of the optimal intervention increases in the size of the liquidity shock, the weight on output relative to inflation and the extent of negative supply effects of the crisis. It decreases in the size of the associated inflation in goods prices which is linked to the possibility to sterilise the intervention and the amount of liquidity initially held by investors.

Furthermore, the anticipation of central bank interventions by private investors leads to a moral hazard effect in the form of less private liquidity provision and thus an increase in the likelihood of financial crises. At the same time, less liquidity provision means more productive investment and thus greater aggregate supply in the absence of a financial crisis. Optimal monetary policy under commitment has to take these additional effects into account.

Motivated by the actual behaviour of the Fed under Alan Greenspan as discussed in section 1.2 and more extensively in Sauer (2007), the paper has concentrated on the optimal monetary policy response to liquidity crises. How-

\footnotetext{
${ }^{54}$ One exception is Caballero and Krishnamurthy (2007) who develop a model of financial crises based on liquidity shortages and Knightian uncertainty aversion in which public and private liquidity serve as complements: The promise by the central bank to provide liquidity in extreme events, i.e. a 'double wave of liquidity shocks' in the model, but not for intermediate events, i.e. only 'one wave' of liquidity shocks, makes private agents provide their own liquidity for intermediate events as they are insured against an uncertain second wave of shocks.
} 
ever, this does not exclude the possibility that other policy tools exist to limit the probability and the extent of such crises. Regulatory measures represent an obvious candidate for appropriate ex ante action, in particular in the light of the external effects of private liquidity provision. A promising proposal seems to be the introduction of procyclical liquidity requirements for financial institutions. Such requirements could help to prevent the buildup of excessive positions in illiquid assets during boom periods via balance sheet feedback effects converse to the ones described in section 4.3 and at the same time limit vicious circles during market downturns (see, e.g., Illing, 2007).

Finally, in view of the substantial growth of financial markets relative to traditional banking in continental Europe and the introduction of new financial instruments like credit derivatives, the concentration on the banking system for financial stability as common in the literature appears to be inadequate. Instead, the understanding of the interlinkages between money, liquidity on financial markets, financial crises, inflation and real production is very important for financial stability and the continuation of successful monetary policy in the future. This paper has provided one step in that direction. The obvious next step is to transfer this model into a stochastic dynamic general equilibrium framework and thus gain additional insights, in particular about the optimal monetary policy under commitment.

\section{Appendix}

\section{A Solution to investors' problem under aggregate risk}

The Lagrangian for the optimal investment decision problem for an individual investor under aggregate risk reads as

$$
\begin{aligned}
\Lambda & =\int_{-\infty}^{\infty}\left\{\gamma \ln \left(c_{1}+\rho z\right)+\beta \ln c_{2}\right. \\
& -\lambda\left[p_{1} c_{1}+p_{2} c_{2}-(w-s)-R s-(R-q) \hat{s}+R z\right] \\
& \left.-\mu\left[p_{1} c_{1}+q \hat{s}-(w-s)\right]\right\} f(\gamma) d \gamma .
\end{aligned}
$$


Using the Leibniz-Rule $\frac{d}{d x} \int_{a}^{b} f(x, z) d z=\int_{a}^{b} \frac{\partial}{\partial x} f(x, z) d z$, i.e. pointwise differentiation, the first-order conditions become

$$
\begin{aligned}
\frac{d \Lambda}{d c_{1}} & =\int_{-\infty}^{\infty}\left(\frac{\gamma}{c_{1}+\rho z}-\lambda p_{1}-\mu p_{1}\right) f(\gamma) d \gamma=0 \\
\frac{d \Lambda}{d c_{2}} & =\int_{-\infty}^{\infty}\left(\frac{\beta}{c_{2}}-\lambda p_{2}\right) f(\gamma) d \gamma=0 \\
\frac{d \Lambda}{d \hat{s}} & =\int_{-\infty}^{\infty}(\lambda(R-q)-\mu q) f(\gamma) d \gamma=0 \\
\frac{d \Lambda}{d z} & =\int_{-\infty}^{\infty}\left(\frac{\gamma}{c_{1}+\rho z} \rho-\lambda R\right) f(\gamma) d \gamma \leq 0 \\
\frac{d \Lambda}{d \lambda} & =\int_{-\infty}^{\infty}\left(-p_{1} c_{1}-p_{2} c_{2}+(w-s)+R s+(R-q) \hat{s}+R z\right) f(\gamma) d \gamma \geq 0 \\
\frac{d \Lambda}{d \mu} & =\int_{-\infty}^{\infty}\left(-p_{1} c_{1}-q \hat{s}+w-s\right) f(\gamma) d \gamma \geq 0 \\
\frac{d \Lambda}{d s} & =\int_{-\infty}^{\infty}(\lambda(R-1)-\mu) f(\gamma) d \gamma \leq 0
\end{aligned}
$$

and $\frac{d \Lambda}{d z} \cdot \int_{-\infty}^{\infty} z f(\gamma) d \gamma=0, \frac{d \Lambda}{d \lambda} \cdot \int_{-\infty}^{\infty} \lambda f(\gamma) d \gamma=0, \frac{d \Lambda}{d \mu} \cdot \int_{-\infty}^{\infty} \mu f(\gamma) d \gamma=0$ and $\frac{d \Lambda}{d s} \cdot \int_{-\infty}^{\infty} s f(\gamma) d \gamma=0$ as complementary slackness conditions.

To derive the expected values of the Lagrangian parameters $\lambda$ and $\mu$ in $t=0$, it is easier to use the optimal values of $c_{1}, c_{2}, \hat{s}, z$ given a realisation of $\gamma$ in $t=1$ and then to integrate over all possible values of $\gamma$ afterwards. This is equivalent to solving for the optimal values of $c_{1}, c_{2}, \hat{s}, z$ given the partial derivatives of the integrands in the first-order conditions above.

$$
\begin{aligned}
& \frac{\partial \Lambda}{\partial c_{1}}=\frac{\gamma}{c_{1}+\rho z}-\lambda p_{1}-\mu p_{1}=0 \\
& \frac{\partial \Lambda}{\partial c_{2}}=\frac{\beta}{c_{2}}-\lambda p_{2}=0 \\
& \frac{\partial \Lambda}{\partial \hat{s}}=\lambda(R-q)-\mu q=0 \\
& \frac{\partial \Lambda}{\partial z}=\frac{\gamma}{c_{1}+\rho z} \rho-\lambda R \leq 0 \\
& \frac{\partial \Lambda}{\partial \lambda}=-p_{1} c_{1}-p_{2} c_{2}+w+(R-1) s+(R-q) \hat{s}-R z \geq 0 \\
& \frac{\partial \Lambda}{\partial \mu}=-p_{1} c_{1}-q \hat{s}+w-s \geq 0
\end{aligned}
$$

and $\frac{\partial \Lambda}{\partial z} z=0, \frac{\partial \Lambda}{\partial \lambda} \lambda=0$ and $\frac{\partial \Lambda}{\partial \mu} \mu=0$ as complementary slackness conditions. Equations (29a) to (29f) and equation (28g) are equations (9a) to (9g) in section 2.3.1.

The first-order condition for optimal investment in the asset is given by equa- 
tion (28g). Using the results for $\lambda$ and $\mu$ from table 2 produces

$$
\begin{aligned}
\frac{d \Lambda}{d s} & =\int_{-\infty}^{\frac{\beta(W-S)}{R S}}\left[\frac{\beta+\gamma}{w+(R-1) s}(R-1)\right] f(\gamma) d \gamma \\
& +\int_{\frac{\beta(W-S)}{R S}}^{\frac{\beta(W-S)}{p_{1} \rho S}}\left[\frac{\beta(W+(R-1) S)}{R S(w+(R-1) s)}(R-1)-\frac{\gamma(W+(R-1) S)}{(w+(R-1) s)(W-S)}+\lambda\right] f(\gamma) d \gamma \\
& +\int_{\frac{\beta(W-S)}{p_{1} \rho S}}^{\infty}\left[\frac{p_{1} \rho(\beta+\gamma)}{R\left(w+\left(p_{1} \rho-1\right) s\right)}(R-1)-\frac{\beta+\gamma}{w+\left(p_{1} \rho-1\right) s}+\lambda\right] f(\gamma) d \gamma \\
& =0 .
\end{aligned}
$$

Solving this using $G(x) \equiv \int_{-\infty}^{x} \gamma f(\gamma) d \gamma$ and $F(x) \equiv \int_{-\infty}^{x} f(\gamma) d \gamma$ with $C I A \equiv$ $\frac{\beta(W-S)}{R S}$ and $L I Q \equiv \frac{\beta(W-S)}{p_{1} \rho S}$ gives

$$
\begin{aligned}
& \frac{\beta(R-1)}{w+(R-1) s} F(C I A)+\frac{(R-1)}{w+(R-1) s} G(C I A) \\
& +\frac{\beta(W+(R-1) S)}{S(w+(R-1) s)}[F(L I Q)-F(C I A)] \\
& -\frac{(W+(R-1) S)}{(w+(R-1) s)(W-S)}[G(L I Q)-G(C I A)] \\
& +\frac{\beta\left(p_{1} \rho-1\right)}{w+\left(p_{1} \rho-1\right) s}[1-F(L I Q)]+\frac{\left(p_{1} \rho-1\right)}{w+\left(p_{1} \rho-1\right) s}[1-G(L I Q)] \\
& =0 .
\end{aligned}
$$

In equilibrium, all investors follow the same investment strategy and the assumption of a mass 1 of ex-ante identical investors makes $s=S$. The definition of conditional expectations

$$
E[\gamma \mid \gamma<x]=\frac{\int_{-\infty}^{x} \gamma f(\gamma) d \gamma}{F(x)}
$$

leads to

$$
G(x)=\int_{-\infty}^{x} \gamma f(\gamma) d \gamma=F(x) E[\gamma \mid \gamma<x]
$$

but this does not allow to solve for $s$ without explicitly parameterising the density function of the liquidity shock $f(\gamma)$. Assuming a uniform distribution for $\gamma$, i.e. $F(x)=\frac{x-a}{b-a}$ for $a \leq x \leq b$, gives the conditional expected value of $E[\gamma \mid \gamma \leq x]=\frac{1}{2}(x+a)$ for $0<a<b$. The definition of the thresholds as $C I A=\frac{\beta(W-S)}{R S}$ and $L I Q=\frac{\beta(W-S)}{p_{1} \rho S}$ results in the conditional expected values $E[\gamma \mid \gamma<C I A]=\frac{1}{2}\left(\frac{\beta(W-S)}{R S}+a\right)$ and $E[\gamma \mid \gamma<L I Q]=\frac{1}{2}\left(\frac{\beta(W-S)}{p_{1} \rho S}+a\right)$. Table 3 in section 2.3.1 summarises this information. 


\section{B Optimal central bank intervention with a quadratic loss function}

In section 3, the loss function (13) of the central bank is linear in the increase of $p_{1}$ above the desired price level $p_{1}^{*}$ and the deviation of aggregate supply $Y_{2}^{s}$ from $\bar{Y}$ caused by liquidations $Z, \Delta(Z)$. This section shows that the results of the model are robust to the loss function (30) that is quadratic in inflation and output deviations from their respective targets, but the first-order condition and thus the comparative static analysis become more complex:

$$
\mathcal{L}_{2}=\left(p_{1}-p_{1}^{*}\right)^{2}+\omega\left(Y_{2}^{s}-\bar{Y}\right)^{2}
$$

The optimisation problem (19) for the central bank becomes

$$
\begin{aligned}
\min _{L} \mathcal{L}_{2} & =\left(p_{1}-p_{1}^{*}\right)^{2}+\omega\left(Y_{2}^{s}-\bar{Y}\right)^{2} \\
& =\left(\frac{1}{1-\tau \rho L}-1\right)^{2}+\omega\left(\bar{Y}-\kappa\left(Z^{*}-L\right)-\bar{Y}\right)^{2} \\
& =\left(\frac{\tau \rho L}{1-\tau \rho L}\right)^{2}+\omega \kappa^{2}\left(\frac{\gamma S-\frac{\beta(W-S)(1-\tau \rho L)}{\rho}}{\beta+\gamma}-L\right)^{2} .
\end{aligned}
$$

The first-order condition turns out to be

$$
\begin{aligned}
\frac{d \mathcal{L}_{2}}{d L} & =\frac{\tau^{2} \rho^{2} L}{(1-\tau \rho L)^{3}}+\omega \kappa^{2}\left(Z^{*}-L\right)\left(\frac{\beta(W-S) \tau}{\beta+\gamma}-1\right) \stackrel{!}{=} 0 \\
& \Leftrightarrow \underbrace{\frac{\tau^{2} \rho^{2} L}{(1-\tau \rho L)^{3}}}_{\text {direct marginal cost of } \frac{d p_{1}}{d L}}+\underbrace{\omega \kappa^{2}\left(Z^{*}-L\right) \frac{\beta(W-S) \tau}{\beta+\gamma}}_{\text {indirect marginal cost of } \frac{\partial Y_{2}^{s}}{\partial Z^{*}} \cdot \frac{\partial Z^{*}}{\partial p_{1}} \cdot \frac{d p_{1}}{d L}}=\underbrace{\omega \kappa^{2}\left(Z^{*}-L\right)}_{\text {marginal benefit of } \frac{\partial Y_{2}^{s}}{\partial L}} .
\end{aligned}
$$

Overall, the quadratic loss function has an impact on the relative size of direct and indirect marginal costs and benefits, but it does not change the general structure of the first-order condition. In particular, the direct marginal cost continues to increase in $L$, while the indirect marginal cost and the marginal benefit decrease with $L$ as $d\left(Z^{*}-L\right) / d L<0$ given the assumptions about the parameters. The optimal $L^{*}$ becomes the solution to a fourth-degree polynomial. With a linear loss function, the last two effects are constant, instead, and $L^{*}$ is the solution to the quadratic equation (20). 


\section{References}

Acharya, Viral V. and Lasse Heje Pedersen (2005): Asset pricing with liquidity risk. Journal of Financial Economics, vol. 77, pp. 375-410.

AlchiAN, Armen A. and Benjamin Klein (1973): On a correct measure of inflation. Journal of Money, Credit, and Banking, vol. 5 (1), pp. 173-191.

Allen, Franklin and Douglas GALE (1994): Limited market participation and volatility of asset prices. The American Economic Review, vol. 84 (4), pp. 933955.

(1998): Optimal financial crises. The Journal of Finance, vol. 53 (4), pp. $1245-1284$.

- (2005): From cash-in-the-market pricing to financial fragility. Journal of the European Economic Association, vol. 3 (2-3), pp. 535-546.

Alvarez, Fernando, Andrew AtKeson and Patrick J. Kehoe (2002): Money, interest rates, and exchange rates with endogenously segmented markets. Journal of Political Economy, vol. 110 (1), pp. 73-112.

Aminud, Yakov and Haim Mendelson (1986): Asset pricing and the bid-ask spread. Journal of Financial Economics, vol. 17 (2), pp. 223-249.

Aminud, Yakov, Haim Mendelson and Lasse H. Pedersen (2005): Liquidity and asset prices. Foundations and Trends in Finance, vol. 1 (4), pp. 269-364.

BAgeHOT, Walter (1873): Lombard Street: A Description of the Money Market. H S King, London.

BERNANKE, Ben and Mark GerTLER (1999): Monetary policy and asset volatility. Economic Review, vol. 84 (4), pp. 17-52. Federal Reserve Bank of Kansas City.

Bernanke, Ben, Mark Gertler and Simon G. Gilchrist (1999): The financial accelerator in a quantitative business cycle framework. In: J. B. Taylor and M. Woodford, eds., Handbook of Macroeconomics, vol. 1, chap. 21. NorthHolland.

BiAis, Bruno, Larry Glosten and Chester SpATt (2005): Market microstructure: A survey of microfoundations, empirical results, and policy implications. Journal of Financial Markets, vol. 8, pp. 217-264.

Brunnermeier, Markus K. and Lasse Heje Pedersen (2005): Predatory trading. The Journal of Finance, vol. 60 (4), pp. 1825-1863. 
(2007): Market liquidity and funding liquidity. New York University, http://pages.stern.nyu.edu/ lpederse/.

BucKs, Brian K., Arthur B. KenNiCKell and Kevin B. MoOre (2006): Recent changes in U.S. family finances: Evidence from the 2001 and 2004 survey of consumer finances. Federal Reserve Bulletin, vol. 92, pp. A1-A38.

CABAllero, Ricardo J. and Arvind Krishnamurthy (2007): Collective risk management in a flight to quality episode. NBER Working Paper No. 12896.

CAMPBELL, John Y. and N. Gregory MANKIW (1989): Consumption, income, and interest rates: Reinterpreting the time series evidence. In: O. J. Blanchard and S. Fischer, eds., Macroeconomics Annual, pp. 185-216. MIT Press, Cambridge, MA.

Cecchetti, Stephen, Hans Genberg, John Lipsky and Sushil WadhWAni (2000): Asset Prices and Central Bank Policy. Geneva Reports on the World Economy. International Center for Monetary and Banking Studies, London.

ChORdia, Tarun, Asani SARKAR and Avanidhar Subrahmanyam (2005): An empirical analysis of stock and bond market liquidity. The Review of Financial Studies, vol. 18 (1), pp. 85-129.

Cifuentes, Rodrigo, Gianluigi Ferrucci and Hyun Song SHIN (2007): Liquidity risk and contagion. Journal of the European Economic Association. Forthcoming.

DANIELSSON, Jon (2001): The emperor has no clothes: Limits to risk modelling. Journal of Banking and Finance, vol. 26 (7), pp. 1273-1296.

DANIELSSON, Jon and Hyun Song SHIN (2003): Endogenous risk. In: Peter Field, ed., Modern Risk Management: A History, chap. 20. Risk Books.

DAVIS, E. Philip (1994): Market liquidity risk. In: D.E. Fair and R. Raymond, eds., The Competitiveness of Financial Institutions and Centres in Europe, pp. 381-402. Kluwer Academic Publishers.

DiAmond, Douglas W. and Philip DyBVIG (1983): Bank runs, deposit insurance, and liquidity. The Journal of Political Economy, vol. 91, pp. 401-419.

DiAmOND, Douglas W. and Raghuram G. RAJAN (2001): Liquidity risk, liquidity creation, and financial fragility: A theory of banking. The Journal of Political Economy, vol. 109 (2), pp. 287-327.

- (2005): Liquidity shortages and banking crises. The Journal of Finance, vol. 60 (2), pp. 615-647. 
(2006): Money in a theory of banking. The American Economic Review, vol. 96 (1), pp. 30-53.

Duffie, Darrell, Nicolae GÂRLEANU and Lasse H. Pedersen (2005): Over-thecounter markets. Econometrica, vol. 73 (6), pp. 1815-1847.

ECB (2001a): Eurosystem to support normal functioning of markets. Press release, 11 September 2001, http://www.ecb.int/press/pr/date/ $2001 / \mathrm{html} /$ index.en.html.

(2001b): Monthly Bulletin October. European Central Bank, Frankfurt.

FAMA, Eugene F. and Kenneth R. FRENCH (1993): Common risk factors in the returns on stocks and bonds. Journal of Financial Economics, vol. 33, pp. 3-56.

FAvero, Carlo, Marco PAgAno and Ernst-Ludwig VON Thadden (2006): How does liquidity affect government bond yields? Mimeo, University of Mannheim.

FreiXas, Xavier, Bruno M. PARIgI and Jean-Charles Rochet (2004): The lender of last resort: A twenty-first century approach. Journal of the European Economic Association, vol. 6 (2), pp. 1085-1115.

Gale, Douglas (2005): Liquidity, interest, and asset prices. Wharton Working Paper No. 05-09, University of Pennsylvania.

GAMmill, James F. and Terry A. MARSH (1988): Trading activity and price behavior in the stock and stock index futures markets in October 1987. The Journal of Economic Perspectives, vol. 2 (3), pp. 25-44.

GARCIA, Gillian (1989): The lender of last resort in the wake of the crash. The American Economic Review, vol. 79 (2), pp. 151-155.

GÂrleanu, Nicolae B. and Lasse H. Pedersen (2007): Liquidity and risk management. The American Economic Review. Forthcoming.

Geithner, Timothy F. (2006): Hedge funds and derivatives and their implications for the financial system. Remarks at the Distinguished Lecture 2006, sponsored by the Hong Kong Monetary Authority and Hong Kong Association of Banks, Hong Kong. http: / / www . newyorkfed. org/ newsevents/speeches/2006/gei060914.html.

Goodhart, Charles and Gerhard Illing, eds. (2002): Financial Crises, Contagion, and the Lender of Last Resort: A Reader. Oxford University Press.

GreensPan, Alan (1987): Statement by Chairman Greenspan on providing liquidity to the financial system. Federal Reserve Bulletin, vol. 73 (12), p. 915. 
(2004): Risk and uncertainty in monetary policy. The American Economic Review, vol. 94 (2), pp. 33-40.

GROMB, Denis and Dimitri VAYANOS (2002): Equilibrium and welfare in markets with financially constrained arbitrageurs. Journal of Financial Economics, vol. 66, pp. 361-407.

Grossman, Sanford J. and Merton H. MiLler (1988): Liquidity and market structure. The Journal of Finance, vol. 43 (3), pp. 617-633.

Holmström, Bengt and Jean TIROLE (1998): Private and public supply of liquidity. The Journal of Political Economy, vol. 106 (1), pp. 1-40.

HUANG, Jennifer and Jiang WANG (2006): Liquidity, asset prices, and welfare under costly participation. The University of Texas at Austin and MIT, http: //www. mccombs . utexas. edu/Faculty/jennifer.huang/.

ILLING, Gerhard (1997): Theorie der Geldpolitik: Eine spieltheoretische Einfürung. Springer-Verlag.

— (2004): Financial fragility, bubbles and monetary policy. In: M. Köthenbürger, H.-W. Sinn and M. Widgren, eds., European Monetary Integration, pp. 141-169. Cambridge, MA, MIT Press.

(2007): Financial stability and monetary policy - A framework. University of Munich, http://www.cesifo-group.de/link/mmi07_ Illing.pdf.

IMF (1998): World Economic Outlook and International Capital Markets: Interim Assessment, chap. Turbulence in Mature Financial Markets, pp. 35-65. International Monetary Fund, Washington, DC.

JORION, Philippe (2000): Risk management lessons from Long-Term Capital Management. European Financial Management, vol. 6 (3), pp. 277-300.

KAUfMAN, George G. (2002): Lender of last resort: A contemporary perspective. In: C. Goodhart and G. Illing, eds., Financial Crises, Contagion, and the Lender of Last Resort: A Reader, pp. 169-185. Oxford University Press.

LACKER, Jeffrey M. (2004): Payment system disruptions and the Federal Reserve following September 11, 2001. Journal of Monetary Economics, vol. 51 (5), pp. 935-965.

LANDON-LANE, John and Filippo OCCHINO (2006): Bayesian estimation and evaluation of the segmented markets friction in equilibrium monetary models. Rutgers University, http: //www.rci.rutgers . edu/ occhino. 
MeYER, Laurence H. (2004): A Term at the Fed - An Insider's View. HarperCollins.

Miller, Marcus, Paul Weller and Lei Zhang (2002): Moral hazard and the US stock market: Analyzing the 'Greenspan put'. The Economic Journal, vol. 112, pp. 171-186.

MORRIS, Stephen and Hyun Song SHIN (1999): Risk management with interdependent choice. Oxford Review of Economic Policy, vol. 15 (3), pp. 52-62.

(2004): Liquidity black holes. Review of Finance, vol. 8, pp. 1-18.

O'HARA, Maureen (1995): Market Microstructure Theory. Blackwell Publishers, Cambridge, Oxford.

PASTOR, Lubos and Robert F. STAMBAUGH (2003): Liquidity risk and expected stock returns. The Journal of Political Economy, vol. 111 (3), pp. 642-685.

PlantIN, Guillaume, Haresh SAPRA and Hyun Song SHIN (2005): Markingto-market: Panacea or pandora's box? Princeton University, http: / / www . princeton.edu/ hsshin/.

SAUER, Stephan (2002): Arbitrage, Liquidity and Systemic Risk - Theoretical Considerations about the Crisis of LTCM (in German). Diplomarbeit, University of Munich.

- (2007): Three liquidity crises in retrospective: Implications for central banking today. Discussion Paper 2007-26, Department of Economics, University of Munich, http://www.sfm.vwl.uni-muenchen.de/stephan. htm.

SCHNABEL, Isabel and Hyun Song SHIN (2004): Liquidity and contagion: The crisis of 1763. Journal of the European Economic Association, vol. 2 (6), pp. 929 968.

SHIN, Hyun Song (2005a): Financial system liquidity, asset prices and monetary policy. In: C. Kent and D. Norman, eds., The Changing Nature of the Business Cycle, pp. 312-335. Reserve Bank of Australia.

- (2005b): Risk and liquidity in a system context. Princeton University, http://www.princeton.edu/ hsshin/.

SHLEIFER, Andrei and Robert W. VISHNY (1992): Liquidation values and debt capacity: A market equilibrium approach. The Journal of Finance, vol. 47 (4), pp. 1343-1366.

(1997): The limits of arbitrage. The Journal of Finance, vol. 52 (1), pp. 35-55. 
TAYLOR, John B. (1993): Discretion versus policy rules in practice. CarnegieRochester Conference Series on Public Policy, vol. 39, pp. 195-214.

(2005): Lessons learned from the Greenspan era. Comment on A. Blinder and R. Reis, Understanding the Greenspan standard. In: The Greenspan EraLessons for the Future. Federal Reserve Bank of Kansas City.

VAYANOS, Dimitri (2004): Flight to quality, flight to liquidity, and the pricing of risk. London School of Economics, http://personal.lse.ac.uk/ vayanos/.

WALsH, Carl E. (2003): Monetary Theory and Policy. MIT Press, Cambridge, MA, 2nd edn.

WeILL, Pierre-Olivier (2007): Leaning against the wind. Review of Economic Studies. Forthcoming.

WiLLIAMSON, Stephen D. (1994): Liquidity and market participation. Journal of Economic Dynamics and Control, vol. 18, pp. 629-670.

WOODFORD, Michael (2003): Interest and Prices: Foundations of a Theory of Monetary Policy. Princeton University Press, Princeton, NJ. 